\title{
Review Article \\ Regulation of Hemichannels and Gap Junction Channels by Cytokines in Antigen-Presenting Cells
}

\author{
Pablo J. Sáez, ${ }^{1}$ Kenji F. Shoji, ${ }^{1}$ Adam Aguirre, ${ }^{1}$ and Juan C. Sáez ${ }^{1,2}$ \\ ${ }^{1}$ Departamento de Fisiología, Pontificia Universidad Católica de Chile, Alameda 340, 6513677 Santiago, Chile \\ ${ }^{2}$ Instituto Milenio, Centro Interdisciplinario de Neurociencias de Valparaíso, Pasaje Harrington 287, Playa Ancha, \\ 2360103 Valparaíso, Chile
}

Correspondence should be addressed to Pablo J. Sáez; pjsaez@uc.cl and Juan C. Sáez; jsaez@bio.puc.cl

Received 10 April 2014; Accepted 19 June 2014; Published 9 September 2014

Academic Editor: Mireia Martín-Satué

Copyright (C) 2014 Pablo J. Sáez et al. This is an open access article distributed under the Creative Commons Attribution License, which permits unrestricted use, distribution, and reproduction in any medium, provided the original work is properly cited.

\begin{abstract}
Autocrine and paracrine signals coordinate responses of several cell types of the immune system that provide efficient protection against different challenges. Antigen-presenting cells (APCs) coordinate activation of this system via homocellular and heterocellular interactions. Cytokines constitute chemical intercellular signals among immune cells and might promote proor anti-inflammatory effects. During the last two decades, two membrane pathways for intercellular communication have been demonstrated in cells of the immune system. They are called hemichannels (HCs) and gap junction channels (GJCs) and provide new insights into the mechanisms of the orchestrated response of immune cells. GJCs and HCs are permeable to ions and small molecules, including signaling molecules. The direct intercellular transfer between contacting cells can be mediated by GJCs, whereas the release to or uptake from the extracellular milieu can be mediated by HCs. GJCs and HCs can be constituted by two protein families: connexins (Cxs) or pannexins (Panxs), which are present in almost all APCs, being Cx43 and Panxl the most ubiquitous members of each protein family. In this review, we focus on the effects of different cytokines on the intercellular communication mediated by HCs and GJCs in APCs and their impact on purinergic signaling.
\end{abstract}

\section{Introduction}

An efficient immune response against pathogens and other challenges requires efficient coordination between different cell types, making cell-cell interaction a key step $[1,2]$. To this end, the immune system uses different types of cellular communication, being the autocrine and paracrine signaling mediated by cytokines two of the most studied ones [3]. These types of signaling allow communication not only among immune cells, but also with resident cells of challenged tissues [4]. This coordination plays a pivotal role in antigenpresenting cells (APCs) activation because they specifically trigger activation of other cells through immunological synapse, such as T- and B-cell activation that mediate adaptive immunity [5], and the cytokines released at this stage determine the onset of the immune response [6].

Cytokines are soluble or membrane-attached proteins that have pro- or anti-inflammatory properties and are produced by immune and nonimmune cells. As expected, the abnormal release of cytokines promotes the development and progression of pathological conditions with rather diverse etiologies, including rheumatoid arthritis, cancer, and even depression [7-9]. In addition, cytokines favor other types of cellular communication through the expression of cell surface molecules [10] and/or release of soluble molecules, as we discuss in the next section. Both of these alternative mechanisms of cellular communication, which are dependent or independent of cellular contacts, might occur through membrane channels constituted by connexins (Cxs) or pannexins (Panxs).

Nowadays, immunologists' rising interest in $\mathrm{Cx}$ - and Panx-based channels is evident in the literature. One of the relevant findings that put GJCs in the center of the immunology field is the contribution to inflammation, antigen presentation, tolerance, HIV sensing, and tumoral immunity [1117]. Here, we review the cytokine regulation of GJCs and HCs in different APCs. 


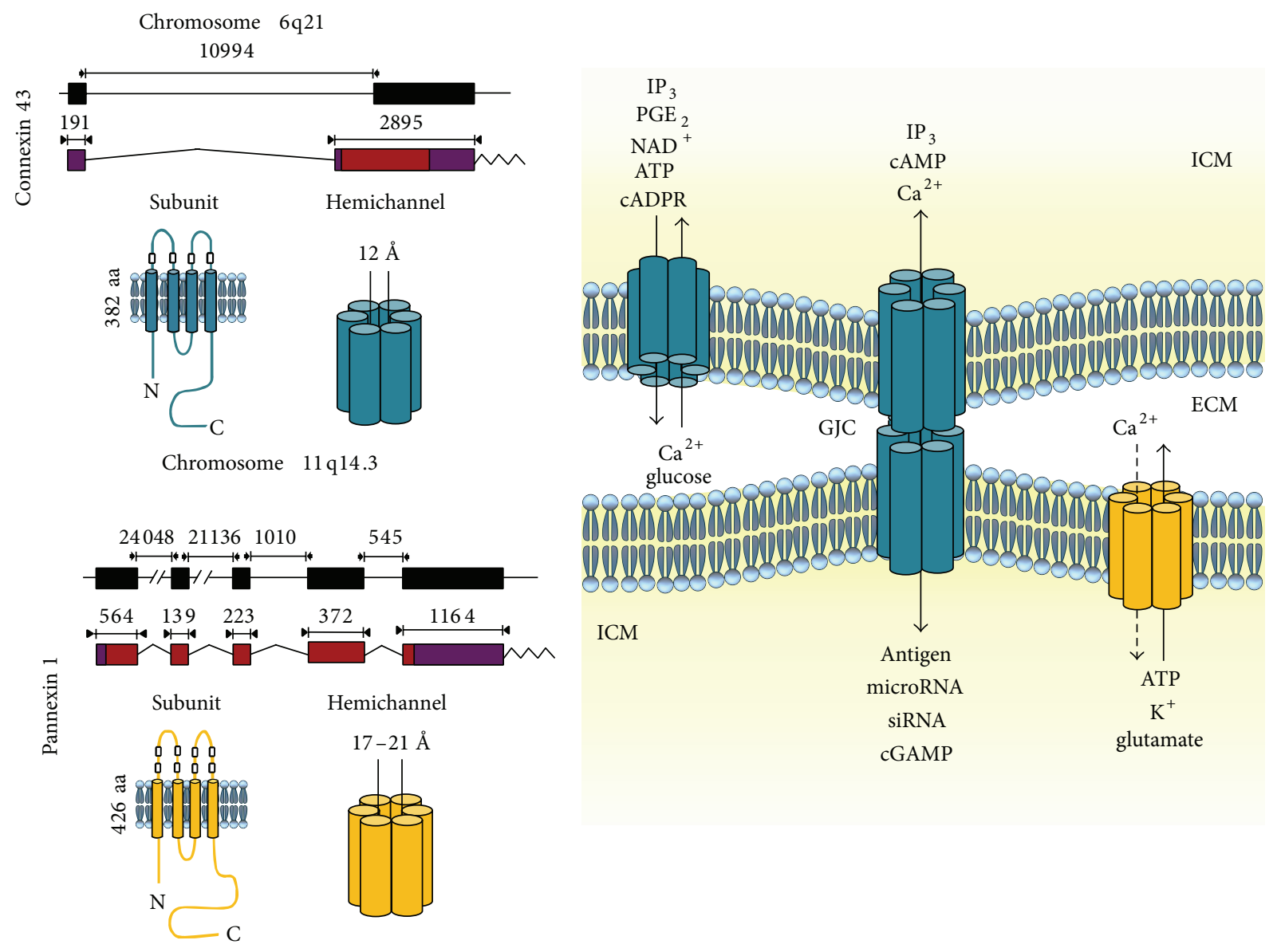

Figure 1: Connexin 43 and pannexin1 at gene and protein levels. Left: a diagram depicting the genomic regions, mRNA, and membrane topology of human connexin 43 (Cx43, top left) and pannexin 1 (Panxl, bottom left). Genomic loci are represented by black boxes that stand for the corresponding exons. mRNA diagrams representing the exons as coding protein regions (red boxes) and $3^{\prime}$ - and $5^{\prime}$-non-coding areas (purple boxes) are shown. The intron lengths are indicated in the schemes of genomic loci, and exon sizes are indicated in the mRNA diagrams. In the membrane topology the white squares indicate extracellular cysteine residues of each protein. Six protein subunits constitute a hemichannel (HC), which has different pore sizes. Right: two adjoining cells forming a gap junction channel (GJC) at the cell interface. Each cell presents HCs formed by $\mathrm{Cx} 43$ or Panxl. Arrows denote the bidirectional communication with the intracellular milieu (ICM) for GJCs and the extracellular milieu (ECM) for HCs; some immunorelevant molecules are shown. Dotted line for $\mathrm{Ca}^{2+}$ permeating Panxl HCs indicates that this phenomenon is not fully demonstrated.

1.1. Gap Junction Channels and Hemichannels. The most studied mechanism of intercellular communication that depends on close cell-cell contact is mediated by gap junction channels (GJCs) [18]. Since most immune cells are generally sparse within tissues, it is possible that this feature delayed the studies on GJCs. Members of the Cx family share the membrane topology and number of units that oligomerize in a GJC (dodecamer) and show high homology in primary sequence (Figure 1) [18-20]. These GJCs are formed by the docking of two adjacent hemichannels (HCs, hexamers) and allow direct contact-dependent cellular communication because they are permeable to ions and small compounds including immunorelevant molecules [13, 21-26].

The turnover of Cxs is between 2 and $3 \mathrm{~h}$ indicating that the strength of intercellular communication can be quickly affected by changes in rate of synthesis and/or degradation of GJC protein subunits. In addition, closure of GJCs can be induced in a few seconds by changes in the state of phosphorylation of Cxs [18]. Therefore, the high plasticity of GJCs is compatible with transient as well as stable gap junctional communication between contacting cells.

Recently, another family of proteins named Panxs and constituted by only three members (Panx1-3) was proposed to form GJCs. Exogenous expression of Panxl alone or with Panx2 establish GJCs in oocytes [27]. Similar findings were obtained with Panxl expression in mammalian cells [28]. Moreover, Panx3 has been proposed to form GJCs between osteoblasts and to contribute to the differentiation of $\mathrm{C}_{2} \mathrm{C}_{12}$ cells into osteoblasts [29]. However, the expression of functional Panx GJCs still remains controversial [30]. Panxs share their membrane topology but show only very little homology in their primary sequence (Figure 1). In addition, $\mathrm{Cx}$ and Panx HCs are oligohexamers [18], but Panx2 has been shown to form octamers [31]. 
HCs are the least studied autocrine/paracrine intercellular communication pathway mainly due to their rather recent discovery. They correspond to one-half of a GJC, and Cx and/or Panx HCs are present in the cell surface of all cells so far studied, allowing the exchange of ions and small molecules between the intra- and extracellular compartments [20]. Cx and Panx HCs differ in their regulation and pore size $[18,20,31]$. Panx1 HCs exhibit a bigger pore vestibule, but the pore neck seems to be more selective than that of $\mathrm{Cx}$ HCs since they are not permeable to anionic molecules $>250$ Daltons [32], whereas several Cx HCs are permeable to Evans blue ( -4 negative charge and $~ 950$ Daltons) [33]. HCs allow communication in a cell-cell contact-independent manner because they permit the release or uptake of small molecules [34, 35].

Several conditions increase the open probability of $\mathrm{Cx}$ HCs including reduction of extracellular or increase of intracellular $\mathrm{Ca}^{2+}$ concentration [36]. In contrast, Panxl HCs are not directly affected by changes in extracellular $\mathrm{Ca}^{2+}$ concentration, but extracellular ATP activation of some P2Y or P2X receptors induces opening of Panxl HCs [37]. Several GJC blockers also inhibit Cx and/or Panx HCs. Extracellular $\mathrm{La}^{3+}$ does not block Cx GJCs [38] or Panx HCs [39] but blocks all Cx HCs so far studied. Nevertheless the use of $\mathrm{La}^{3+}$ should be accompanied by using other blockers because it has been shown to block other membrane channels [40].

Cx43 and Panxl, the most ubiquitous members of each family of HC forming proteins, are expressed in APC [14, $20,34,41,42]$. Cytokine regulation of intercellular communication through GJCs and HCs might contribute to a rapid amplification and coordination of activating or inhibitory signals among neighboring cells. Here, we summarize the current knowledge on the regulation of both types of cellular communication by cytokines.

1.2. Immunorelevant Molecules and Cx- and Panx-Mediated Cell-Cell Communication. The study of GJCs began in the early 60 s with the description of the structure responsible for intercellular electrical transmission [43]. These studies showed current transference between contacting excitable cells and were the first to use the term gap junction to identify this structure [44-47]. In the 70s, the permeation of different immunorelevant molecules was described. These studies included small peptides [48], $\operatorname{IP}_{3}$ [49], and cAMP [50], but the study of Cxs and Panxs in immune cells had to wait for almost 30 years to be reported.

Although the presence of GJCs at ultrastuctural level was shown at the end of the 80 s during antigen presentation $[38,51,52]$, immunologists put an eye on the GJC field after the demonstration of antigen transfer (linear peptides up to $1,800 \mathrm{kDa}$ ) through GJCs in APCs [25]. This direct antigen transfer through GJCs allows cross-presentation, which corresponds to presentation of antigens in major histocompatibility complex (MHC) class I molecules by APCs that acquire antigens from infected or tumoral cells and after presentation to $\mathrm{T}$ cells initiating an effective immune response $[24,25]$. Following this, our group and collaborators were able to show the transference of tumoral antigens between dendritic cells after stimulation with tumoral necrosis factor- $\alpha$ (TNF- $\alpha$ ) and tumoral lysate [24]. In addition, GJCs allow cell-cell transference of single- and double-stranded RNA [53], as well as specific single-stranded microRNA [23], which has a high impact on immune responses [54]. Recently, the cell-cell transference of two different microRNAs (miR-142 and -223) between macrophages was demonstrated [55]. These data open new unexplored fields in the study of GJCs, which might be used for specific delivery of microRNA and siRNA. Whether Cx or Panx HCs allow the transfer of single- or double-stranded RNA has to be studied.

$\mathrm{Ca}^{2+}$ signaling plays a pivotal role in immune cells and contributes to all stages of the immune response. In APCs, it contributes directly to their migration, maturation, and cell death [56]. The transference of second messengers associated with $\mathrm{Ca}^{2+}$ signaling, such as $\mathrm{IP}_{3}$, through GJCs was demonstrated several years ago $[22,49]$. In addition, $\mathrm{IP}_{3}$ is released through HCs [57], and intracellular $\mathrm{IP}_{3}$ contributes to increase $\mathrm{HC}$ activity [58]. $\mathrm{IP}_{3}$ contributes to different steps of the immune response [59] and plays an important role in migration of dendritic cells (DCs) [60]. Then, it is possible to hypothesize that transference of $\mathrm{IP}_{3}$ between communicating DCs or release/uptake through HCs might have an impact on the phenotype of DCs. Moreover, direct $\mathrm{Ca}^{2+}$ transfer occurs via GJCs [26], and it is possible that similar $\mathrm{Ca}^{2+}$ communication occurs through DC-T-cell GJCs during immune synapse $[13,61]$. In addition, it was shown recently that $C x[36,62-67]$ and Panx HCs $[28,29]$ provide a new route for $\mathrm{Ca}^{2+}$ entry into the cell. Then, the functional expression of HCs in immune cells might also contribute to the $\mathrm{Ca}^{2+}$ signaling.

CD38 is an ectoenzyme expressed by myeloid and lymphoid cells that use $\mathrm{NAD}^{+}$to generate cADPR and ADPribose, which contribute to several immune cell responses [68]. Interestingly, $\mathrm{NAD}^{+}$permeates GJCs $[22,69]$ and $\mathrm{Cx}$ $\mathrm{HCs}[22,70]$, and upon activation of $\mathrm{P} 2 \mathrm{X}_{7}$ receptors increase the opening of Panxl HCs [71]. It can be anticipated that $\mathrm{NAD}^{+}$transfer or release through these channels might contribute to cell-cell communication in different immune cells. In addition, cADPR uptake occurs through Cx43 HCs [72], which in turn contributes to microglial survival [73].

ATP is a recognized DAMP that activates immune cells and also contributes to autocrine and paracrine activation when released from cells $[34,74,75]$. The contribution of $\mathrm{Cx}$ and Panx HCs to purinergic signaling has been reported and was recently revised [76]. Thus, $\mathrm{Cx}$ and Panx HC-mediated ATP release might play a role in all steps of the immune response. In contrast to ATP, prostaglandins (PGs) are small soluble molecules that seem to contribute to anti-inflammation in APCs, although this feature depends on the microenvironmental signals [77]. In particular, $\mathrm{PGE}_{2}$ contributes to induce gap junctional communication [78] and also is released through $\mathrm{Cx} 43 \mathrm{HCs}$ [79]. Moreover, $\mathrm{PGE}_{2}$ and purinergic signaling contribute to interleukin (IL) $1 \beta$ release from macrophages [80]. Thus, $\mathrm{PGE}_{2}$ and other metabolites produced by cyclooxygenase- 2 might be released from APCs (and/or other immune cells), which produce a different signature in the involved cells depending on the inflammatory mediators that coexist with them. 


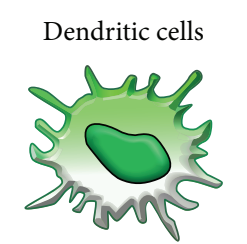

Cxs: 43(GJCs, HCs), 45

Panxs: 1 (HCs?)

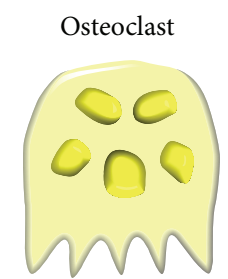

Cxs: 43 (HCs and GJCs)

Panxs: 1? 3?

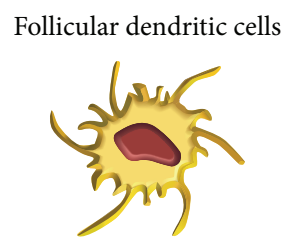

Cxs: 43 (GJCs)

Panxs: 1 (HCs?)

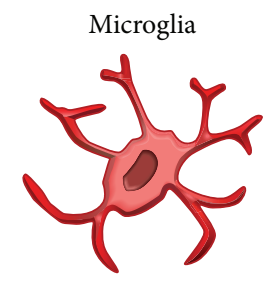

Cxs: 32 (HCs), 36, 43

(GJCs, HCs), 45

Panxs: 1 (HCs)

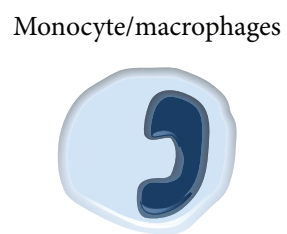

Cxs: 37 (HCs), 43 (GJC, HCs)

Panxs: 1 (HCs)

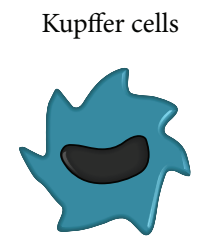

Cxs: 43 (GJCs)

Panxs: 1

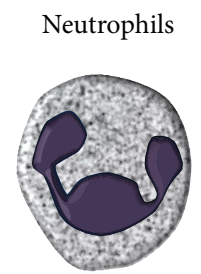

Cxs: 37 (HCs), 40, 43

(GJCs?, HCs)

Panxs: 1 (HCs)

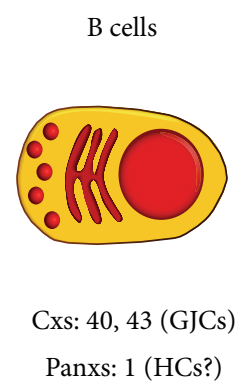

Panxs: 1 (HCs?)

FIGURE 2: Connexin and pannexin expression in antigen-presenting cells. Summary scheme shows the expression of gap junction channels (GJCs) and hemichannels (HCs) formed by connexins (Cxs) and pannexins (Panxs) in different antigen-presenting cells (APCs). Question marks next to a protein (Cx or Panx) or channel type (GJC or HC) indicate that the expression or function remains unknown or is not fully shown.

Description of functional GJCs in T cells occurred almost 4 decades ago $[81,82]$. However, a rising interest in T-cell GJCs began very recently after the discovery of their role in regulatory T cells- (Tregs-) mediated tolerance [12]. GJCs allow cAMP transfer from Tregs to naïve $\mathrm{T}$ cells and provide immunosuppression [12]. In addition, GJCs between DCs and Tregs contribute to prevent the activation of $\mathrm{CD} 8^{+} \mathrm{T}$ cells [15], showing that GJCs provide amplification of activating or inhibitory signals.

The role of $\mathrm{Cx}$ - and Panx-based channels in infectious diseases is well documented [83], but an unexpected role was recently shown in the development of HIV infection. Cytosolic DNA-sensing occurs through an enzyme called cyclic guanosine monophosphate-adenosine monophosphate (cGAMP) synthase (cGAS) [84], which produces the second messenger cGAMP that enables DCs to sense HIV [85]. Importantly, transfer of cGAMP occurs through GJCs between $\mathrm{Cx} 43$ and $\mathrm{Cx} 45$ overexpressing cells [21]. This spreading of cGAMP activates STING (from stimulator of IFN genes) in the receiving cell, which in turn produces interferon (IFN) [21]. Since DCs and other APCs express Cx43 and Cx45 (Figure 2) [24, 86, 87], it is possible that gap junctional communication between these cells contributes to the HIV immune response.

\section{Expression of Cxs in Antigen-Presenting Cells}

Although GJCs in immune cells were described in the early 70 s by Hülser and Peters who reported gap junctional communication between T cells $[81,82]$, the study of Cxs in APCs had to wait until the end of the decade when expression of GJCs and gap junctional communication was shown in macrophages $[88,89]$. Later, they were found in DCs [51, 52, 90] and follicular DCs [91-93]. On the other hand, the study of HCs in the immune system started several years ago. Later in the 90s, Alves et al. (1996) showed ATP-induced dye uptake in macrophages, which was suggested to be mediated by HCs [94]. This study was followed by studies in microglia, neutrophils, and T cells several years later $[34,41,95,96]$.

2.1. Dendritic Cells (DCs). Ralph Steinman in the early 70 s discovered the DCs [97], which emerge in the bone marrow from a myeloid common precursor and populate different organs [98]. In these cells, the expression of Cxs has been demonstrated, but the expression of Panxs remains unknown. However, the expression of Panxl might be predicted by the ATP-induced dye uptake observed in these cells [99-102]. In addition, Panxl expression has been detected at the mRNA level in DCs under resting conditions, while its upregulation has been demonstrated upon exposure to bacterial lipopolysaccharide (LPS) or IFN- $\gamma$ in DCs $[103,104]$. LPSinduced IL- $1 \beta$ release in DCs occurs in a $\mathrm{P}_{2} \mathrm{X}_{7}$ receptorindependent way [105], suggesting that $\mathrm{P} 2 \mathrm{X}_{7}$ receptormediated opening of Panxl might not contribute to inflammasome activation. However, whether Panxl might contribute to other responses in DCs has not been reported yet. Here, we present evidence of Panxl presence in $\mathrm{CD}_{11 c^{+}} \mathrm{DCs}$ from mouse spleen (Figure 3).

In murine and human DCs (primary cultures and cell lines), the expression of $\mathrm{Cx} 43$ and $\mathrm{Cx} 45$ has been demonstrated at the mRNA and protein levels (Figure 2) $[13,15$, 

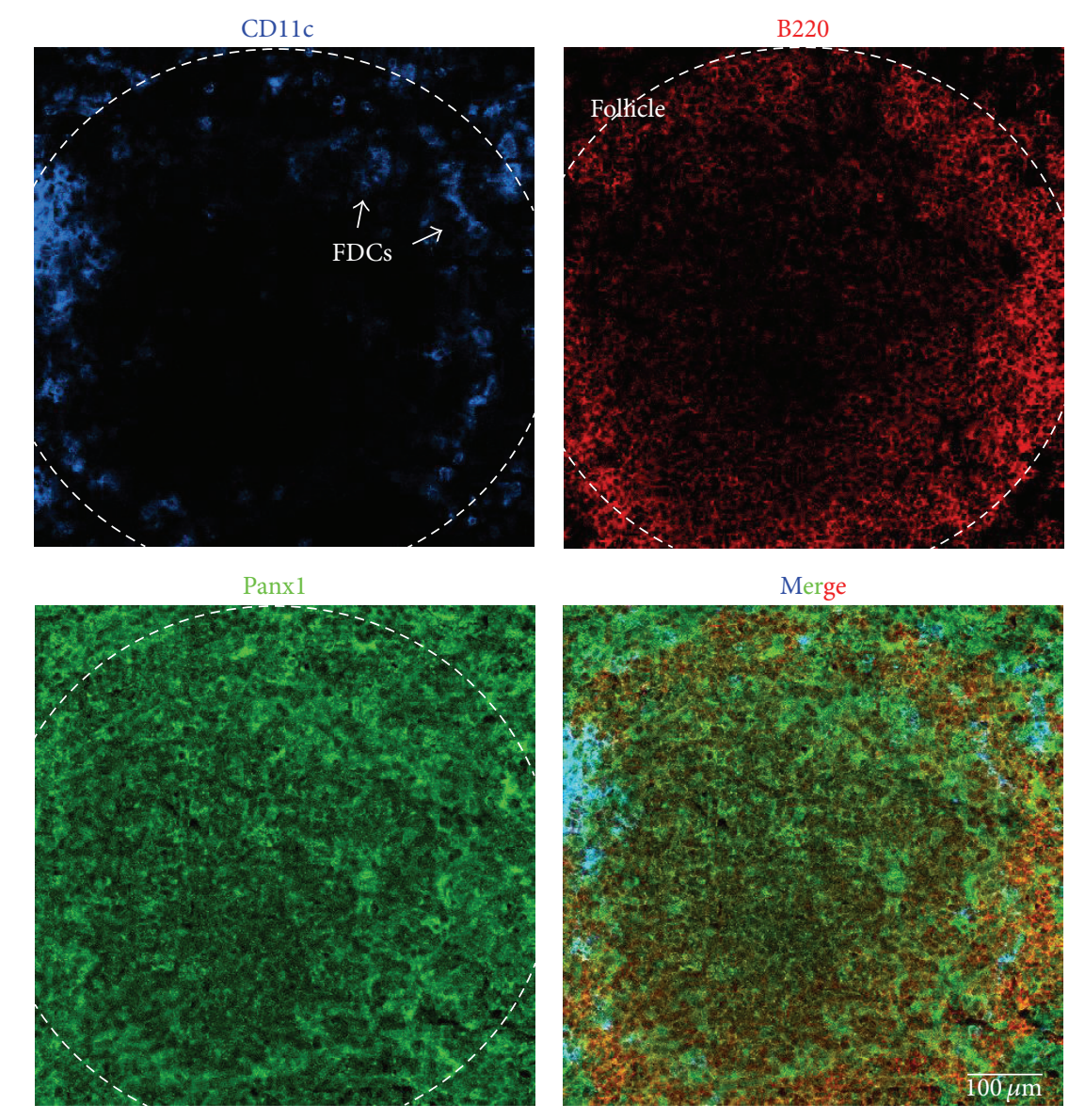

FIGURE 3: Dendritic and B cells of mouse spleen present pannexinl. Immunofluorescence of adult mice spleen cryosections $(8 \mu \mathrm{m}$ thick) fixed in ethanol $(70 \% \mathrm{v} / \mathrm{v})$ at $-20^{\circ} \mathrm{C}$ for $20 \mathrm{~min}$, mounted in Fluoromount-G and observed in a confocal microscope (Olympus, FluoView FV1000). Pannexinl (Panxl in green: primary antibody: rabbit anti-Panxl antibody and secondary antibody goat anti-rabbit IgG conjugated to FITC) immunoreactivity is shown. Cells were identified by their reactivity to specific antigens as follows: dendritic cells (DCs) by CD1lc (blue, monoclonal mouse antibody conjugated to allophycocyanin) and B cells by B220 (red, monoclonal mouse antibody conjugated to phycoerythrin) in a follicle. Arrows denote follicular DCs (arrows). Merge is also shown. Scale bar: $100 \mu \mathrm{m}$.

$24,61,86,87,93,106,107]$. In addition, migratory DEC205 ${ }^{+}$ DCs, found at draining lymph nodes after muscle damage, show increased immunoreactivity for Cx43 and Cx45 [86]. Consistent with the requirement of cell activation for $\mathrm{Cx}$ expression, $\mathrm{Cx} 43$ was not detected in skin DCs under resting conditions [108]. Similarly, Cx43 was found to contribute to the establishment of oral tolerance, because it mediates antigen transfer from $\mathrm{CD}_{103}{ }^{+} \mathrm{DC}$ s to macrophages in murine intestine [106]. Accordingly, expression of Cxs and functional state of GJCs are modulated by different cytokines (Table 1).

TNF- $\alpha$ is a proinflammatory cytokine and possibly the most relevant one because it is the first cytokine released by different cell types, including DCs, after exposure to different stimuli, such as cell damage or infection, and its receptor is expressed by all APCs [109]. However, TNF- $\alpha$ alone does not increase Cx43 total protein levels in murine or human DCs $[24,86]$ but potentiates the expression of functional GJCs between cultured DCs in combination with IL-1 $\beta$ or a tumoral lysate (Table 1) $[24,86]$. Whether TNF- $\alpha$ induces HC activity in DCs remains unknown.
IL-1 $\beta$, another proinflammatory cytokine released by different cell types including APCs, is maintained as an inactive precursor and after cleavage is released as a mature bioactive form to the extracellular milieu [110]. Similar to TNF- $\alpha$, IL-1 $\beta$ alone does not induce gap junctional communication or Cxs expression but, in combination with TNF- $\alpha$, induces GJCs and increases $\mathrm{Cx} 43$ and $\mathrm{Cx} 45$ levels in DCs (Table 1) [86]. The possible effect of IL- $1 \beta$ on the expression of HCs in DCs has not been reported yet.

IFN- $\gamma$ contributes to the control of viral infections and is mostly produced by $\mathrm{T}$ and natural killer (NK) cells, but it is also produced and released by DCs [111-114]. Similar to TNF- $\alpha$ and IL- $1 \beta$, treatment with IFN- $\gamma$ does not induce gap junctional communication or increase in Cx43 levels [87] but, in combination with TNF- $\alpha$ and IL-1 $\beta$, promotes a synergic response on $\mathrm{Cx} 43$ and $\mathrm{Cx} 45$ levels in DCs [86]. Moreover, in combination with LPS, IFN- $\gamma$ potentiates the functional expression of GJCs in DCs [87] and prolongs the TNF$\alpha / \mathrm{IL}-1 \beta$-induced dye coupling [86], showing that IFN- $\gamma$ is an enhancer rather than inducer of gap junctional communication. In addition, we show here that IFN- $\gamma$ induces dye 
TABLE 1: Effect of different cytokines on GJCs and HCs in different antigen-presenting cells.

\begin{tabular}{|c|c|c|c|}
\hline Cytokine(s) & Cell type & Effect on Cx or Panx expression & $\begin{array}{l}\text { Effect on GJCs, HCs and } \\
\text { technique used }\end{array}$ \\
\hline \multirow{8}{*}{ TNF- $\alpha$} & \multirow{2}{*}{ DCs } & $=\mathrm{Cx} 43(\mathrm{~Wb})[24]$ & $=\mathrm{GJCs}(\mathrm{DT})[24,86]$ \\
\hline & & +MCL: $\uparrow \mathrm{Cx} 43(\mathrm{~Wb})[24]$ & +MCL $\uparrow$ GJCs $[24]$ \\
\hline & Mo & $\mathrm{NE}$ & $=\mathrm{GJCs}(\mathrm{DT})[140]$ \\
\hline & \multirow{4}{*}{ Microglia } & $\uparrow \mathrm{Cx} 32$ (FC) [187] & $\uparrow \mathrm{HCs}(\mathrm{MR}, \mathrm{DU})[187,192]$ \\
\hline & & $\uparrow \mathrm{Cx} 43(\mathrm{~Wb})[192]$ & 个GJCs (SL) [192] \\
\hline & & +ATP: $\uparrow C x 43$, Panx1 (Wb) [96] & +LPS $\uparrow G J C s[196]$ \\
\hline & & & $\begin{array}{l}=\text { GJCs }[96] \\
+ \text { ATP } \uparrow \text { GJCs (DT) [96] } \\
+ \text { ATP } \leftrightarrow \text { HCs (DU) }[96]\end{array}$ \\
\hline & Neutrophils & +CM: $\uparrow \mathrm{Cx} 37,40,43$ (Wb, IF) [217] & +CM $\uparrow \mathrm{GJCs}(\mathrm{DT})$ [217] \\
\hline \multirow{2}{*}{$\mathrm{IL}-1 \beta$} & DCs & $\mathrm{NE}$ & $=\mathrm{GJCs}(\mathrm{DT})[86]$ \\
\hline & Microglia & $\mathrm{NE}$ & $=$ GJCs $(\mathrm{DT})[96]$ \\
\hline \multirow{7}{*}{ IFN- $\gamma$} & \multirow{3}{*}{ DCs } & \multirow{3}{*}{$=\mathrm{Cx} 43(\mathrm{~Wb})[87]$} & $=$ GJCs $(\mathrm{DT})[86]$ \\
\hline & & & $\uparrow \mathrm{HCs}(\mathrm{DU})$ \\
\hline & & & +LPS $\uparrow G J C s[87]$ \\
\hline & \multirow{2}{*}{ Mo } & \multirow{2}{*}{$\mathrm{NE}$} & $=\mathrm{GJCs}(\mathrm{DT})[140]$ \\
\hline & & & +LPS $\uparrow$ GJCs $[140]$ \\
\hline & $\mathrm{KCs}$ & $=\mathrm{Cx} 43(\mathrm{RT}, \mathrm{Wb})[168]$ & 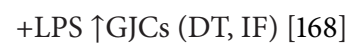 \\
\hline & Microglia & $\mathrm{NE}$ & $=\mathrm{GJCs}(\mathrm{DT})[96]$ \\
\hline \multirow{3}{*}{ IL-6 } & \multirow{2}{*}{ DCs } & \multirow{2}{*}{$\mathrm{NE}$} & $=\mathrm{GJCs}(\mathrm{DT})[86]$ \\
\hline & & & $\uparrow \mathrm{HCs}$ (DU) \\
\hline & Microglia & $\mathrm{NE}$ & $=\mathrm{GJCs}(\mathrm{DT})[96]$ \\
\hline RANKL & OCs & $\mathrm{NE}$ & १GJCs? $\uparrow H C s ?[178]$ \\
\hline CXCL12 & B cell & $\uparrow \mathrm{Cx} 43$ Phosphorylation (Wb) & $=\mathrm{HCs}$ \\
\hline RANKL/M-CSF & OCs & $\uparrow \mathrm{Cx} 43(\mathrm{RT}, \mathrm{Wb})[176]$ & $\uparrow G J C s(I F)[176]$ \\
\hline IFN- $\gamma /$ IL-6 & DCs & ND & $=\mathrm{HCs}(\mathrm{DU})$ \\
\hline \multirow{2}{*}{ TNF- $\alpha / \mathrm{IL}-\beta$} & DCs & $\uparrow \mathrm{Cx} 43(\mathrm{RT}, \mathrm{Wb})[86]$ & 个GJCs (DT) [86] \\
\hline & Microglia & $\uparrow \mathrm{Cx} 43$, Panx1 (Wb) [96] & $\uparrow \mathrm{GJCs}(\mathrm{DT})[96]$ \\
\hline \multirow{3}{*}{ TNF- $\alpha /$ IFN- $\gamma$} & DCs & ND & $=\mathrm{GJCs}(\mathrm{DT})[86]$ \\
\hline & Mo & $\uparrow \mathrm{Cx} 43(\mathrm{~Wb})[140]$ & 个GJCs (DT, IF) [140] \\
\hline & Microglia & $\uparrow \mathrm{Cx} 43$, Panxl (Wb) [96] & $\begin{array}{l}\uparrow \mathrm{GJCs}(\mathrm{DT})[96,196] \\
\uparrow \mathrm{HCs}(\mathrm{DU})[96]\end{array}$ \\
\hline TNF- $\alpha /$ IL- $\beta /$ IFN- $\gamma$ & DCs & $\uparrow \mathrm{Cx} 43$ (RT, Wb) [86] & $\uparrow$ GJCs (DT) [86] \\
\hline \multirow{2}{*}{ TNF- $\alpha / \mathrm{IL}-\beta / \mathrm{IL}-6$} & DCs & $\mathrm{NE}$ & $\downarrow$ GJCs (DT) [86] \\
\hline & Microglia & $\downarrow \mathrm{Cx} 43$, Panxl (Wb) [96] & $\begin{array}{l}\downarrow \text { GJCs (DT) [96] } \\
\downarrow \text { HCs (DU) [96] }\end{array}$ \\
\hline \multirow{2}{*}{ TNF- $\alpha /$ IFN- $\gamma /$ IL- 6} & DCs & $\mathrm{NE}$ & $\downarrow$ GJCs (DT) \\
\hline & Microglia & $\downarrow \mathrm{Cx} 43, \operatorname{Panxl}(\mathrm{Wb})[96]$ & $\begin{array}{l}\downarrow \text { GJCs (DT) [96] } \\
\downarrow \text { HCs (DU) [96] }\end{array}$ \\
\hline TNF- $\alpha /$ IL-1 $\beta /$ IFN- $\gamma /$ IL- 6 & DCs & $\mathrm{NE}$ & $\downarrow$ GJCs (DT) [86] \\
\hline
\end{tabular}

CM: conditioned medium, DCs: dendritic cells, DT: dye transfer, DU: dye uptake, FC: flow cytometry, IF: immunofluorescence, KCs: Kupffer cells, LPS: bacterial lipopolysaccharide, MCL: melanoma cell lysate, Mo: monocyte, NE: not evaluated, OCs: osteoclasts, RT: reverse transcription polymerase chain reaction, SL: scrape loading, and Wb: Western blot. Effect on HC or GJC activity: no effect $(=)$, upregulation $(\uparrow)$, and downregulation of induced activity $(\downarrow)$.

uptake sensitive to $\mathrm{La}^{3+}$, suggesting that the IFN- $\gamma$-induced dye uptake is mediated by Cx HCs (Figures 4(a) and 4(b)).

IL-6, described initially as a stimulating factor for IgG production in $\mathrm{B}$ cells, is a cytokine produced by almost all nucleated cells [115] and drives T helper 17 (Th17) differentiation and inhibits Tregs [116, 117]. However, IL6 also shows anti-inflammatory effects as it decreases the reducing immune response and promotes the release of anti-inflammatory cytokines after exercise, such as IL-10 and transforming growth factor- $\beta$ (TGF- $\beta)[118,119]$. From 

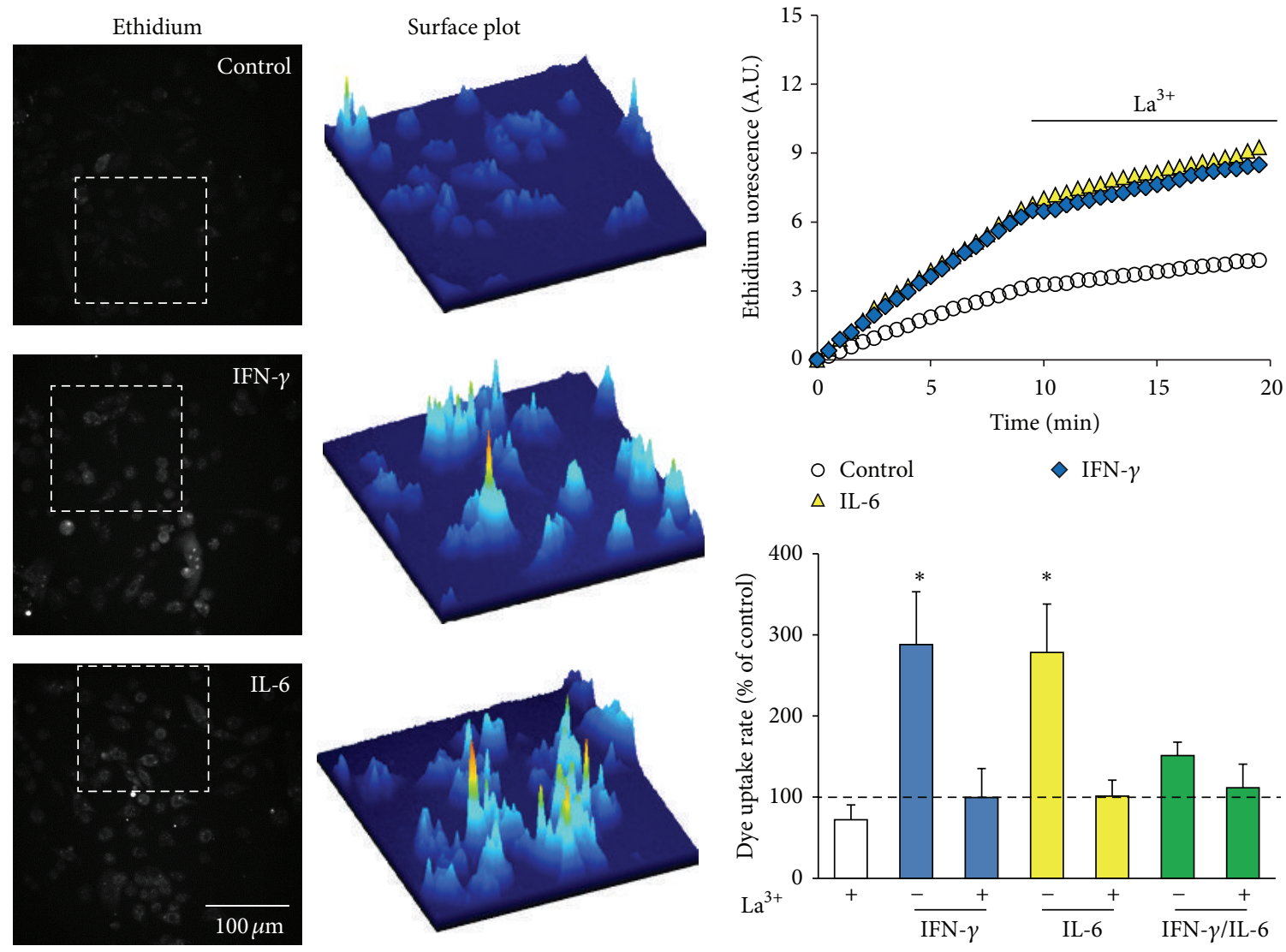

(a)

(b)

FIGURE 4: IFN- $\gamma$ or IL-6 increases dye uptake in dendritic cells. Bone-marrow-derived dendritic cells (BMDCs) from balb/c mice were differentiated with $40 \mathrm{ng} / \mathrm{mL}$ GM-CSF and IL- 4 for 7 days. At day 7, BMDCs were treated for $6 \mathrm{~h}$ with IFN- $\gamma(10 \mathrm{ng} / \mathrm{mL})$, IL-6 (10 ng/mL), or both, and ethidium uptake was evaluated in time-lapse experiments (Olympus BX 51W1I). (a) Left: fluorescence images of ethidium after 9 min of uptake. Scale bar: $50 \mu \mathrm{m}$. Right: ImageJ surface plot analysis of fluorescence intensity of the region indicated in the field (dotted square). (b) Top: time-lapse ethidium uptake under control conditions (white circles) or after $6 \mathrm{~h}$ treatment with IL-6 (yellow triangles) or IFN- $\gamma$ (blue diamonds). Each point corresponds to the mean of 30 cells. After 10 min of recording, $\mathrm{La}^{3+}(200 \mu \mathrm{M})$ was added to the bath solution to block connexin hemichannels. Bottom: graph showing the basal dye uptake rate and the effect of $\mathrm{La}^{3+}$ on BMDCs after treatment with IFN- $\gamma$ (blue bars), IL-6 (yellow bars), or both (green bars). Each bar corresponds to the mean \pm SE (\% of control condition, dotted line) of 3 independent experiments.

the GJCs perspective, IL- 6 has an anti-inflammatory effect because it prevents the TNF- $\alpha / \mathrm{IL}-\beta$ - and TNF- $\alpha / \mathrm{IL}-\beta / \mathrm{IFN}-$ $\gamma$-induced gap junctional communication in DCs [86]. Similar findings related to cytokine-regulation in microglia are discussed below. In this review, we present relevant data showing that IL-6 induces dye uptake in DCs in a similar way to IFN- $\gamma$ and is blocked by $\mathrm{La}^{3+}$, consistent with $\mathrm{Cx} \mathrm{HC}$ mediated response (Figure 4(b)). Interestingly, IL-6 antagonizes IFN- $\gamma$-induced dye uptake, which is correlated with its role in the maintenance of immature DCs [120]. This phenomenon might be promoted by downstream signaling pathways triggered by these cytokines that activate different suppressors of cytokine signaling proteins [121]. These data suggest that the effect of IL-6 on HC activity of DCs depends on the cytokine context present in the cellular microenvironment.

With these findings, it is plausible to anticipate that Tcell polarization is determined by the cytokine profile of the microenvironment, as well as by molecules directly exchanged and/or released to the extracellular milieu via GJCs and/or HCs, respectively, expressed by DCs and T cells.

2.2. Langerhans Cells (LCs). These cells were described almost 150 years ago by Paul Langerhans [122], but their role remains elusive over almost 100 years until they were described as leukocyte derived cells [123]. LCs reside in skin epidermis and represent the first barrier against pathogens and external noxa [124]. Although LCs are less motile than dermal DCs [125], they are better APCs [126], suggesting their important role in antigen presentation. LCs are characterized by the expression of the nonpolymorphic class I MHC molecule CD1a and C-type lectin Langerin, as well as the presence of Birbeck granules, which are tennis-racquetshaped intracytoplasmic organelles [127-129]. When LCs capture antigens, they migrate to skin draining lymph nodes 
(LNs) where they present antigens to naïve T cells [129] and might induce or suppress the immune response [130]. Early studies performed by Concha et al. observed at ultrastuctural level that physical interactions between LCs and T cells during allogeneic antigen presentation includes the presence of GJC-like structures [51, 52, 90].

Cx43 immunoreactivity was found in LC-like cells in human tissue with LC histiocytosis [91] and in $\mathrm{MHCII}^{+}$epidermal LC-like cells from human epidermis [25]. However, Zimmerli et al. detect no Cx43 immunoreactivity in LCs (CDla ${ }^{+}$epidermal cells) from normal human skin [108]. This discrepancy could be explained in part by the inflammatory state of the tissue. Whether the tissue is under resting state or inflammation might affect the $\mathrm{Cx} 43$ expression, as occurs with the upregulation of $\mathrm{Cx} 43$ expression after stimulation in other immune cells. In support of the Cx expression, gap junctional communication between LCs has been shown to allow the transfer of antigenic peptides in a $\mathrm{Cx} 43$-dependent manner [25]. However, the possible functional expression of Cx HCs remains unknown.

Panxl and Panx3 expression have been reported in murine epidermis [131], but their expression in LCs has not been documented. However, functional expression of Panx HCs is suggested by ATP-induced dye uptake in murine and human LCs [102, 132]. Since LCs express several purinergic receptors that contribute to the LC-mediated immune response [133], it is conceivable to suggest that Panx HCs might also contribute to cytokine release and activation of LCs.

2.3. Follicular Dendritic Cells. Unlike DCs, follicular DCs (FDCs) present a low phagocytic activity but high retention of antigen and immune complexes on their surfaces. They reside at follicles of secondary lymphoid organs [134], where they present antigens to B cells [135]. The origin of FDCs is a controversial topic because some evidences show that they emerge from bone marrow, while other studies propose that they derive from mesenchymal cells [134]. This controversy might have contributed to delay the establishment of primary cultures of FDCs and the subsequent demonstration of cellcell communication mechanisms mediated by $\mathrm{Cx}$ - and Panxbased channels.

In situ hybridization studies showed Cx43 mRNA in human tonsils [93]. In addition, it was demonstrated that Cx43 colocalizes with FDC markers (CD21 and CD35) at germinal centers of human tonsils and spleen [91-93]. Moreover, gap junctional communication among FDCs and between FDCs and B cells has been demonstrated at functional and ultrastructural levels [91-93]. Here, we show that FDCs $\left(\mathrm{CD}_{11 c^{+}}\right)$found in mouse spleen follicles present Panxl immunoreactivity (Figure 3 ). The expression of functional HCs on FDCs remains unknown, but currently it is possible to speculate that TNF- $\alpha$ [134], crucial cytokine for development of FDCs, might modulate the expression of GJCs and HCs, as it occurs in other APCs. Similarly, IL-6 might affect $\mathrm{HC}$ activity in FDCs because these cells are the main source of this cytokine at germinal centers [134].
2.4. Monocyte/Macrophages. Monocytes emerge from the same precursor of DCs in the bone marrow and circulate in the blood [98]. Upon tissue injury, they rapidly extravasate and differentiate in DCs or macrophages, depending on the cytokine pattern present in the microenvironment $[136,137]$. Studies on GJCs in APCs started with demonstrations of gap junctional communication between macrophages [88, 89], and information on the expression of Cxs and Panxs in these cells is increasing progressively [55, 106, 138-143]. Recently, it was shown that tumor-associated macrophages express $\mathrm{Cx} 43$, and it seems that they form GJCs in long networks [139]. Similarly, alveolar macrophages form communicating networks with epithelial cells in the alveoli where they coordinate $\mathrm{Ca}^{2+}$ signaling [144]. This cell-cell communication might be protective effect because specific deletion of $\mathrm{Cx} 43$ in macrophages increases the release of proinflammatory cytokines [144]. In addition, monocytes and macrophages form heterocellular GJCs with $\mathrm{CD}_{103}{ }^{+} \mathrm{DCs}$, endothelial cells, and T cells [106, 140-142, 145].

Resting monocytes express Cx37 and, after activation, they also express $\mathrm{Cx} 43$. These Cxs regulate their adhesion and extravasation, respectively (Figure 2) [140, 142, 146, 147]. In support of this notion, TNF- $\alpha$ has been shown to increase Cx43 expression, adhesion, and extravasation of monocyte/ macrophages $[140,142]$. Treatment with TNF- $\alpha$ alone does not induce functional expression of GJCs in monocytes, but it remains to be demonstrated whether it induces $\mathrm{Cx} 43 \mathrm{HC}$ activity, which might be involved in cell adhesion $[142,146]$, as it has been demonstrated for Cx37 HCs [147]. IFN- $\gamma$ does not induce the expression of HCs or GJCs but increases Cx43 levels, gap junctional communication, and in vitro migration when combined with LPS or TNF- $\alpha$ (Table 1) [140].

The expression of Panxs in monocytes was first suggested by ATP-induced dye uptake [148]. Recently, it was demonstrated that human monocytes express Panxl under resting conditions, and its total levels are upregulated after treatment with LPS [138]. In monocytes, LPS induces functional expression of Panxl HCs, which contributes to ATP release and consequently to IL-1 $\beta$ release [138].

Peritoneal, alveolar, and cell lines derived from macrophage express $\mathrm{Cx} 37$ and $\mathrm{Cx} 43$ under resting conditions, and upregulation of $\mathrm{Cx} 43$ expression is observed after activation [55, 72, 94, 144, 147, 149-155]. In macrophages, Cx37 negatively regulates cell adhesion as in monocytes [147], while Cx43 has been proposed to play a role in phagocytosis [150]. However, the latter remains controversial [153]. These particularities might rely on the different genetic background (mice strain, heterozygotes, or K.O.) and protocols used. Moreover, $\mathrm{Cx} 43 \mathrm{HCs}$ allow the release of small signaling molecules including ATP and $\mathrm{NAD}^{+}$and also contribute to IL-1 $\beta$ release in macrophages infected with Bacillus anthracis $[72,149,156]$. In addition, it has been recently shown nitric oxide release through HCs [157] and thus, it is possible that $\mathrm{Cx} 37$ and/or $\mathrm{Cx} 43 \mathrm{HCs}$ allow nitric oxide release in activated monocyte/macrophages [158]. Macrophages also express Panxl HCs, which are activated by extracellular ATP [159]. This finding was suggested previously in studies where HC blockers were shown to reduce the ATP-induced dye uptake in peritoneal macrophages and in a macrophage cell line $[94,152]$. 

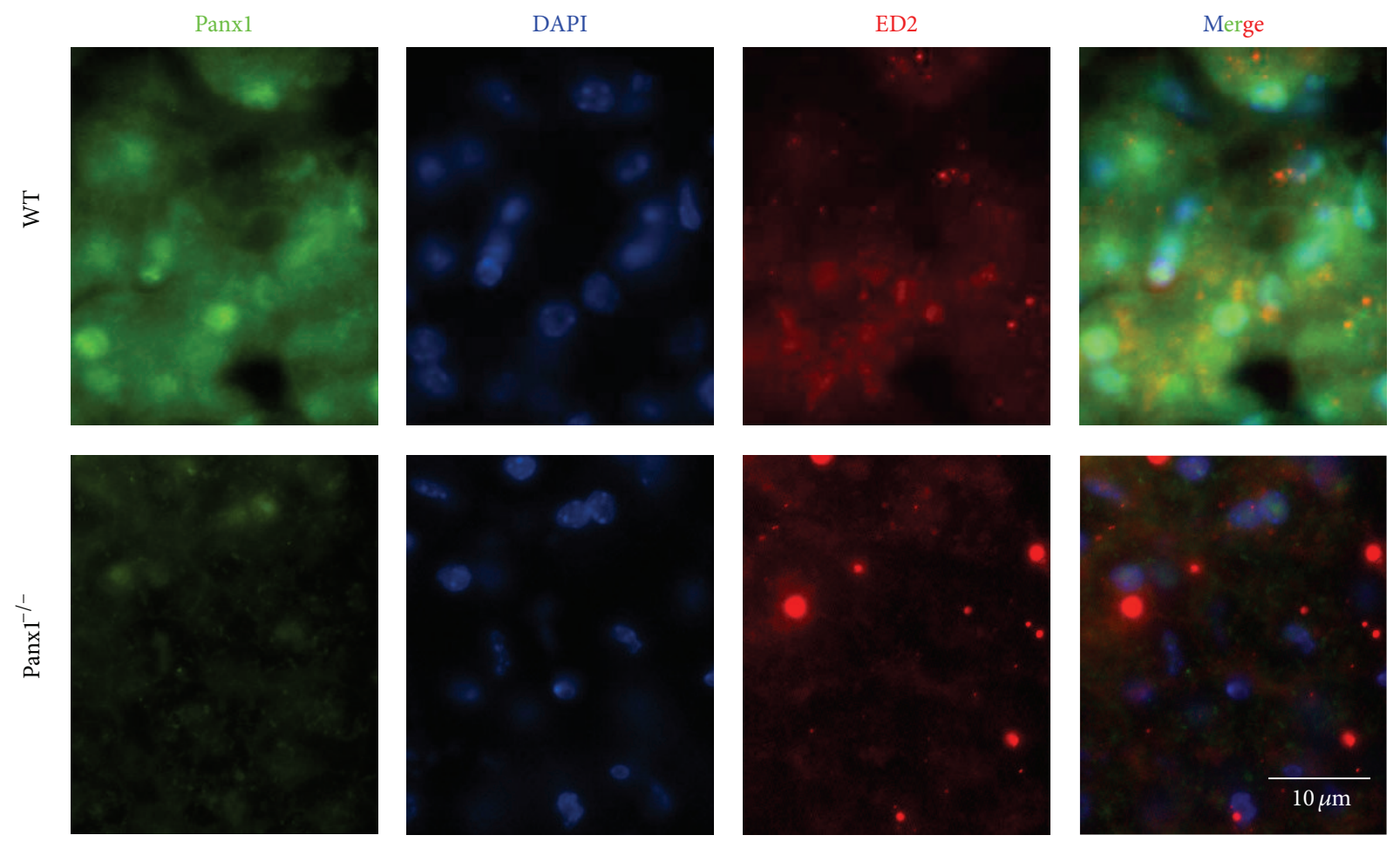

FIGURE 5: Expression of pannexin1 (Panxl) in Kupffer cells. Immunofluorescence analysis of liver cryosections ( $8 \mu \mathrm{m}$ thick) obtained from adult wild-type (WT) and Panx1 ${ }^{-/-}$adult (C57/BL6) mice was performed to analyze reactivity of Panxl (green, primary antibody: rabbit anti-Panx1 antibody and secondary antibody goat anti-rabbit IgG conjugated to FITC) in ED2 (red: goat polyclonal antibody and secondary antibody mouse anti-goat conjugated to Cy3) positive cells, which correspond to Kupffer cells. Top panels correspond to a liver section of a WT mouse and bottom panels correspond to a liver section of a Panx1 $1^{-/-}$mouse. No specific Panxl reactivity was detected in Panx1 $1^{-/-}$ liver, but ED2 positive cells were evident. DAPI stain was used to visualize nuclei (blue), and merge is also shown. Panxi ${ }^{-/-}$mice were kindly donated by Dr. Hanna Monyer (University of Heidelberg, Germany). Bar: $10 \mu \mathrm{m}$.

In macrophages, Panxl HCs contribute to IL-1 $\beta$ release through a pathway independent of their permeability [37], but to our knowledge the possible functional regulation of these channels by cytokines has not been described. However, an interesting suggestion of the possible regulation of Panxl by cytokines was investigated by gene expression pattern in macrophage polarization [160]. Macrophages present different phenotypes depending on the stimuli and the microenvironment cytokine signature. Then, "classic" activation of macrophages with LPS or cytokines such as TNF- $\alpha$ or IFN$\gamma$ leads to a proinflammatory profile, which is named M1 [161]. Conversely, "alternative" activation after exposure to IL4, IL-10, or IL-13 or particular Toll-like receptor agonists leads to macrophage differentiation with an anti-inflammatory profile, which is named M2 [161]. Interestingly, while M1 polarization induces downregulation of Panxl expression in macrophages, M2 polarization induces some upregulation [160]. These observations suggest the involvement of Panx1 in the anti-inflammatory response of M2 macrophages, but whether functional Panx1 HC activity is increased in M2 has not been published yet. Altogether, these data suggest that $\mathrm{Cx}$ and Panx HCs play an important role in macrophage activation; their possible regulation by pro- or anti-inflammatory cytokines is a vast unexplored field of research.
2.5. Kupffer Cells. Kupffer cells (KCs) are the largest population of resident macrophages in the body, the liver being their organ of residence $[137,162]$. These cells have the ability to present antigens, undergo fusion, form large multinucleated cells, and induce Tregs activation and degradation of intravascular debris [137, 163-165]. Under resting state, KCs release anti-inflammatory cytokines promoting tolerance [163], but after stimulation they release proinflammatory cytokines and might present antigens to $\mathrm{CD} 4^{+}$(helper) and $\mathrm{CD}^{+}$ (cytotoxic) T cells $[166,167]$.

In the liver, KCs are sparse, but under proinflammatory conditions they form aggregates and present increased $\mathrm{Cx} 43$ immunoreactivity at KC-KC interface, suggesting GJC formation in vivo $[168,169]$. In support of this notion, cultured KCs express low Cx43 mRNA and protein levels but do not communicate through GJCs under resting conditions (Figure 2). However, after exposure to LPS/IFN- $\gamma$, cultured KCs enhance the expression of $\mathrm{Cx} 43$ (Table 1) that is located at $\mathrm{KC}-\mathrm{KC}$ interface allowing gap junctional communication [168]. Neither Panxs nor Cx HCs have been demonstrated in KCs. Here, we show the presence of Panxl in KCs recognized by their ED2 reactivity in wild-type mice (Figure 5). Consistently, Panxl was not detected in ED2 reactive cells in liver sections of Panxl ${ }^{-/-}$mice (Figure 5). Functional expression of 
Panxl HCs in KCs and their possible regulation by cytokines still remain unknown.

2.6. Osteoclasts. Osteoclasts (OCs) are large multinucleated macrophages located in bones. They can be derived from bone marrow precursors or monocytes and have boneresorbing activity $[137,162,170]$. Because autoimmune diseases lead to bone destruction (e.g., rheumatoid arthritis) [170], a rising interest in the study of the interplay between skeleton and the immune system (osteoimmunology) has taken place during the last decade. Several cytokines, including IL-17, type I and II IFNs, and receptor activator of nuclear factor kappaB ligand (RANKL), have the ability to induce osteoclastogenesis, the process that modulates bone remodeling $[170,171]$. Conversely, under noninflammatory conditions, OCs present antigens to CD4 and CD8 T cells, which differentiate into regulatory $\mathrm{T}$ cells and inhibit bone resorption [171].

Cx43 mRNA and protein have been detected in cultured OCs and also at the bone (Figure 2) [172-182]. OCs derived from bone marrow precursors or monocytes that undergo fusion and form multinucleated tartrate-resistant acid phosphatase (TRAP) positive cells with bone-resorbing activity express $\mathrm{Cx} 43$, which contributes to fusion as observed by the use of Cx43 blockers [180, 181]. Considering the involvement of $\mathrm{Cx} 43$ in fusion of OC precursor and the fact that osteoclastogenesis is inhibited by osteoprotegerin released from stromal/osteoblast lineage cells $[173,175]$, it is possible that under normal conditions osteoprotegerin downregulates Cx43 and then prevents fusion of precursors. Interestingly, a cytokine member of the TNF family named RANKL induces osteoclastogenesis in combination with macrophage colony-stimulating factor (M-CSF) and also increases Cx43 expression (Table 1) [176].

Ultrastructural evidence of GJCs between OCs has been reported $[177,182]$, but the functional expression of GJCs has been only suggested. The contribution of GJCs to the boneresorbing activity has been addressed by using HC blockers [178-181], but still leaving open the possibility that OCs may also express $\mathrm{Cx}$ or Panx HCs. For instance, the expression of Panxl HCs could be feasible because these contribute to macrophage fusion, which leads to multinucleated cell formation [183]. In addition, immunofluorescence analysis of bones shows that most cells presented Panx3 at the growth plate [29], suggesting that OCs might express this protein. Finally, Cx43, forming either GJCs or HCs, is involved in the development of rheumatoid arthritis because silencing Cx43 in rat lower limbs reduces the number of OCs and delays the onset of this disease [174]. This suggests that $\mathrm{Cx} 43$ expression by OCs might contribute to the development of this disease and might be a relevant target for its treatment.

2.7. Microglia. Microglia, the main resident macrophage of the central nervous system, remove dead cells and monitor cell microenvironment. After injury or infection, activated microglia secrete proinflammatory cytokines and present antigens. In addition, deregulation of their activation is a hallmark of neurodegenerative diseases [184-186].
The study of Cxs and Panxs in microglia has been extensive. The expression of Cxs 32, 36, and 43 and Panx1 has been reported. Some of these proteins form functional GJCs and HCs that contribute to cell-cell communication, migration, and neuronal death (Figure 3) [41, 95, 96, 187-197]. In addition, the mRNA of Cx45 was found in mouse but was not detectable in human microglia [194]. Cx43 seems to play a relevant role because its total protein levels are upregulated in microglia activated by advanced glycation endproducts, amyloid- $\beta$ peptide, DAMPs, PAMPs, cytokines, and a $\mathrm{Ca}^{2+}$ ionophore [96, 189, 192, 193, 195-197]. Indeed, microglia treated with advanced glycation endproducts, proinflammatory cytokines, PAMPs, and a $\mathrm{Ca}^{2+}$ ionophore form GJCs presumably constituted by $\mathrm{Cx} 43[192,193,195]$. In support of this position, the specific blockade or lack of $\mathrm{Cx} 43$ in microglia of Cx43 K.O. mice abrogates the cytokine-induced GJCs [96, 196].

Gap junctional communication between microglia is tightly regulated by several cytokines (Table 1). In fact, intercellular communication mediated by GJCs is increased in microglia after treatment with TNF- $\alpha$, TNF- $\alpha / \mathrm{IFN}-\gamma$, and TNF- $\alpha /$ IL-1 $\beta[96,192,196]$. Shaikh et al. [192] demonstrated gap junctional communication after treatment with TNF- $\alpha$ in a microglial cell line, but a recent study performed by Sáez et al. [96] showed that TNF- $\alpha$ does not induce dye coupling in primary cultures of microglia. However, there are several differences that might explain this discrepancy: (1) one study evaluated dye coupling through scrape loading while the other used microinjection; (2) both studies used different TNF- $\alpha$ concentrations; and (3) one study used a microglial cell line and the other used primary cultures of microglia. Consequently, the interpretation of these results should be taken cautiously and the protocols reconsidered.

Recently, it was shown that extracellular ATP is required by the cytokine-induced GJCs and forces the early onset of this gap junctional communication [96], showing a synergistic effect between cytokines and DAMPs. As observed in DCs by Corvalán et al. [86], IL-6 prevents the induction of GJCs in microglia by preventing upregulation of $\mathrm{Cx} 43$ and Panxl, as well as by increasing free intracellular $\mathrm{Ca}^{2+}$ levels [96]. Furthermore, it is possible that IL-6 might disrupt cell adhesion between microglia as shown in other cells [198], and consequently it might also prevent the formation of GJCs. Recently, absence of dye transfer between microglia in vivo and between microglia and other brain cells has been shown in both resting and injury conditions [143]. This study assessed dye transfer by using sulforhodamine $B$ and previous studies that demonstrated gap junctional communication in microglia used Lucifer yellow [96, 192, 193, 195, 196]. The difference in the method used to evaluate functional gap junctional communication is relevant because GJCs are selective to molecules with different size and charges. In particular, Cx43 GJCs are less permeable to cationic than anionic dyes [199-201]. In addition, microglial GJCs were recently identified at ultrastructural level in situ between microglia and neural cell progenitors and also with nonidentified cells [202]. These data correlate with immunoreactivity of $\mathrm{Cx} 43$ at sites of apposition between the aforementioned 
cells [202]. Finally, whether microglia establish GJCs in vivo allowing permeation of signaling or immunorelevant molecules remains controversial.

Recently, the expression of functional Cx and Panx HCs has been shown in microglia $[73,96,187,189,203,204]$. Treatment with amyloid- $\beta$ peptide increases $\mathrm{Cx} 43 \mathrm{HC}$ activity in microglial response, which in turn allows glutamate and ATP release [189]. Cx43 HC activity and ATP release are also increased by TNF- $\alpha / \mathrm{IFN}-\gamma$, but these two reactions are prevented by IL-6 [96]. These studies show that ATP is released through Cx43 HCs, although ATP might also be released by exocytosis [205]. In addition, Cx32 HC activity is increased in microglia treated with TNF- $\alpha$ and/or LPS, which induce glutamate release $[187,203,204]$. These findings suggest that a similar outcome in $\mathrm{HC}$ activity results from the action of different stimuli that trigger different intracellular signaling cascades.

A similar mechanism commands Panxl HC activity, which can be enhanced by amyloid- $\beta$ peptide and contributes to glutamate and ATP release [189]. In addition, TNF- $\alpha / \mathrm{IFN}-$ $\gamma$ increases Panxl HC activity, leading to ATP release [96]. Moreover, microglial Panx1 HCs present an increased activity after exposure to high concentrations of ATP, which favor microglial migration $[96,190,191]$. Although exposure to TNF- $\alpha /$ IFN- $\gamma$ or TNF- $\alpha /$ IL- $1 \beta$ does not affect the basal ATPinduced HC activity in microglia, IL- 6 prevents the induction of Panx $\mathrm{HC}$ activity in cells treated with proinflammatory cytokines [96]. This inhibitory effect of IL-6 might downregulate microglial migration, as shown by arachidonic acid that closes Panxl HCs [188]. Conversely to migration, Panxl does not contribute to microglia proliferation at embryonic stages [206]. To sum up, these results suggest that microglia might migrate toward amyloid- $\beta$ peptide plaques or ATP foci in a Panxl-dependent manner.

In addition, several studies show increased dye uptake or molecule release (e.g., ATP, glutamate) in activated microglia [192, 204, 207-209], but the use of Cx and Panx HC blockers (e.g., carbenoxolone) does not dissect the molecular entity that mediates the dye uptake. However, these experiments unveil that $\mathrm{Cx}$ and Panx HCs may contribute to neuronal death and host defense against pathogen infections. The latter seems to be mediated by IL-1 [208, 209]. In addition, recent studies show that $\mathrm{HC}$ blockers delay the development of Alzheimer' disease, amyotrophic lateral sclerosis, and multiple sclerosis in murine models of these diseases [204, 207], suggesting that HC blockers might be useful as a therapeutical approach to the treatment of these diseases. Interestingly, it was shown that carbenoxolone delays the onset of multiple sclerosis in mice by preventing the release of IL-23 from microglia and the polarization of Th17 cells [210]. Related to this last study, it may be possible that microglia communicate with $\mathrm{T}$ cells through $\mathrm{Cx}$ - and Panxl-based channels, determining the polarization of T cells. However, the heterocellular expression of GJCs between microglia and $\mathrm{T}$ cells, or the regulation of $\mathrm{Cx}$ - and Panx-based channels by IL-17, has not been addressed yet.

2.8. Neutrophils. These circulating leukocytes are the most abundant in the blood (50-70\%), the first cells that arrive at the injury site after detection of chemokines and cytokines, and the first responders to most injuries sites. In addition, a new role has been shown in the maintenance of longlived B cells by interacting at marginal zone in spleen $[211,212]$. Although neutrophils express low or no MHC II and costimulatory molecules under resting conditions exposure to different cytokines, as occurring in chronic pathologies, leads to upregulation of MHC II expression in neutrophils and they acquire APC characteristics [213, 214]. Moreover, neutrophils perform MHC I-mediated crosspresentation and MHC II-mediated antigen presentation to $T$ cells $[214,215]$. In addition, murine neutrophils act as APCs and contribute to Th1 and Th17 cells polarization in vitro in absence of exogenous cytokines, and as expected those effects were MHC II-dependent [216]. Importantly, neutrophil-T-cell interaction promotes Th17 cell polarization independent of TGF- $\beta$ and IL- 6 , suggesting that contactdependent intercellular communication plays an important role in this process [216]. Thus, it is currently considered that neutrophils participate not only in early stages of innate immune responses, but also in further stages of adaptive immune responses, making their cellular interactions key steps for coordinating immune responses.

The study of Cxs in neutrophils began just two decades ago, and now it has been expanded to Panxs. Although no Cxs are detected in mouse or human circulating neutrophils, they expressed Cxs 37, 40, and Cx43 at mRNA and protein level after activation [17, 217-219]. However, some studies did not detect Cx43 in human blood neutrophils [220, 221]. However, this was expected considering that neutrophils were not stimulated.

Neutrophils form aggregates and communicate to each other through GJCs only after LPS or TNF- $\alpha$ exposure and in the presence of a cytokine containing endothelial cellconditioned medium [217]. Nevertheless, the exact cytokine (or cytokine mixture) that induces expression of GJCs in neutrophils remains unknown. Additionally, neutrophils form functional GJCs with endothelial cells, which favor their neutrophil migration $[142,219]$. In fact, there is ultrastructural evidence of gap junction formation between neutrophils and endothelial cells after ischemic injury [141]. Interestingly, TNF- $\alpha$ increases the neutrophil adhesion to endothelial cells as well as the migration in vivo in a Cx43-dependent manner [142]. However, in vitro studies have shown that TNF- $\alpha$ reduces the gap junctional communication between these cells [219], probably through a downregulation of endothelial Cxs. However, this apparent controversy might be due to differences between in vivo and in vitro studies, as well as the endothelial cell type used, timing of the response, stage of recruited neutrophil, and differences in microenvironment signals that command the inflammatory process. Similar differences occur in studies of neutrophil interactions with epithelial cells. While in vivo studies show that $\mathrm{Cx} 43$ contributes to neutrophil migration across an alveolar epithelial barrier in response to LPS [220], in vitro studies show absence of gap junctional communication between neutrophils and airway epithelial cells [221]. In addition, and supporting the contribution of $\mathrm{Cx} 43$ to cell-cell communication between the endothelium and neutrophils during extravasation, in several 
studies downregulation of $\mathrm{Cx} 43$ reduces levels of neutrophil extravasation after burn injury, wound healing, and spinal cord damage [222-224]. Conversely, Cx40 deletion did not affect neutrophil migration [225], and the contribution of this protein to neutrophil activation is still unknown.

The expression of $\mathrm{Cx}$ and Panx HCs has been demonstrated in neutrophils. After activation, neutrophils present Cx43 reactive puncta on their surface [217] and release ATP through $\mathrm{Cx} 43 \mathrm{HCs}$ that favor migration without effect on adhesion to endothelial cells [218, 219]. Moreover, Panxl HCs play a key role during neutrophil chemotaxis because their surface expression is polarized toward the leading edge where they allow ATP release and thus provide guidance for neutrophil migration $[34,226,227]$. It remains to be studied whether cytokines regulate $\mathrm{Cx}$ or Panx $\mathrm{HC}$ activity in neutrophils.

2.9. B Cells. B cells are also APCs because they present antigens in $\mathrm{MHC}$ II to $\mathrm{CD}^{+} \mathrm{T}$ cells, which induce antibody production [135]. During this activation, B cells polarize toward the synapse, which determines whether the cell becomes effector or memory B cell [228, 229].

Expression of Cxs 40 and 43 has been demonstrated in isolated human B cells and at germinal centers of tonsil $[92,93]$. Cx43 is also expressed in splenic B cells and some cell lines [230, 231]. Although endogenous functional expression of HCs remains unknown, Cx43 overexpression increases membrane permeability in a B cell line as expected [232]. Cx43 contributes to B cell spreading and adhesion. In fact, mutations that block the channel function of $\mathrm{Cx} 43$ impair the B-cell receptor- (BCR-) mediated spreading [230, 232]. However, $\mathrm{Cx} 43$ mutant expressed by B cells retained the ability to rearrange the cytoskeleton, conversely to B cells expressing a Cx43 with deletion of C-terminal. Unexpectedly, in this study no increase in dye uptake in resting or activated wild type B cells was found. In addition, blockade of HCs did not produce changes in BCR-induced cell spreading [232], suggesting that in these cells $\mathrm{Cx} 43$ contributes with a role to the intracellular signaling. It is worth mentioning that $\mathrm{Cx} 43$ colocalizes with actin in B cells and acts as a downstream signal for CXCL12-induced activation of Rap1 [233]. Moreover, downregulation of Cx43 impairs the CXCL12-induced migration and transendothelial migration [233], but whether $\mathrm{HC}$ activity contributes to $\mathrm{B}$ cell migration has not been studied yet.

Panxl expression in B cells has not been reported, and unlike $\mathrm{T}$ cells there is no further evidence to suggest that $\mathrm{B}$ cells increase membrane permeability under certain conditions. Here, we present evidence that Panxl is expressed in B220 ${ }^{+}$B cells in mouse spleen (Figure 3 ). Moreover, freshly isolated murine B cells present Panxl at the cell surface, suggesting that it might form functional HCs (Figure 6). Finally, although ATP stimulation did not induce dye uptake in B cells, it remains to be demonstrated whether antigen triggering affects the activity of Panxl HCs.

Early studies showed the formation of GJCs between B cells and T cells that contribute to IgM synthesis [231], and also between B cells and FDCs [92, 93], suggesting a role for GJCs in B cell activation at immunological synapses. However, it is still unknown whether cytokines affect GJCs or HCs in B cells. Moreover, it remains to be elucidated whether other soluble cytokines such as IL-6, APRIL, BAFF, and TNF- $\alpha$ regulate the functional state of GJCs and/or HCs.

\section{Concluding Remarks}

The immune response efficiency relies on several homocellular and heterocellular interactions, which provide amplification to this response. Immune cells use different types of cellular communications, such as cytokines [3], exosomes [234], tunneling nanotubes [235], GJCs [17], and HCs. As shown here, all APCs express Cxs and/or Panxs and, in general, they are upregulated or redistributed after activation. GJCs and HCs contribute to almost all stages of the classical innate and adaptive immune response (Figure 7).

After injury, GJCs and HCs contribute to leukocyte extravasation [140-142, 146, 147, 219]. Panx1 HCs contribute to the recruitment of neutrophils and microglia toward the injury site [191, 227]. Although it remains controversial, it has been proposed that $\mathrm{Cx} 43$ contributes to phagocytosis [158]. Moreover, activated DCs, monocytes, macrophages, neutrophils, and microglia can communicate through GJCs [24, 86, 87, 96, 168, 176, 192, 196, 217], and HCs have been demonstrated in some of them. At this step, gap junctional communication might amplify the immune response because APCs might share specific information as antigen peptides $[24,25]$, which will increase the number of responding cells. Migratory DCs that arrive to lymph nodes present increased levels of Cx43 and Cx45 [86]. Recently, the expression of functional GJCs between DCs and T cells during immune synapse was shown to contribute to T-cell activation $[13,61]$, as it was previously suggested (Figure 7) [42, 52, 90, 236]. Prior to DC-T cell interaction, guidance of T-cell migration by extracellular signals induce specific $\mathrm{Ca}^{2+}$ dynamics that allow the establishment of kinapses and synapses, which correspond to short and long lasting interactions between these cells, respectively [237, 238]. Interestingly, recently it was shown that paracrine purinergic signaling modulates $\mathrm{Ca}^{2+}$ signaling in T cells in a $\mathrm{P}_{2} \mathrm{X}_{4}$ and $\mathrm{P} 2 \mathrm{X}_{7}$ receptor-dependent manner, which ultimately reduce their motility [239]. Then, it is possible to anticipate that HCs might contribute to ATP release from mature DCs, which in the lymph nodes will help to establish DC-T-cell contact leading to antigen presentation.

It has been reported in vitro as well as in situ that human naïve $\mathrm{CD}^{+} \mathrm{T}$ cells establish GJCs with melanoma target cells, contributing to their activation, but not to their lytic function [240]. Conversely, human NK cells establish GJCs with DCs and tumor cells in a $\mathrm{Cx} 43$-dependent process that contributes to NK cell-mediated lysis and further antitumoral immunity (Figure 7) [107]. Moreover, GJCs between polarized T cells (Th1 or Th2) have also been demonstrated [145]. Interestingly, Th1 and Th2 cells form GJCs with macrophages, but Th2 cells present lower levels of Cx43 [145], suggesting the possible involvement of other Cxs in this process. Similar to Th2 cells, in Th17 cells Cx43 is absent [241]. However, the expression of GJCs in these cells has not been shown. In addition, here 

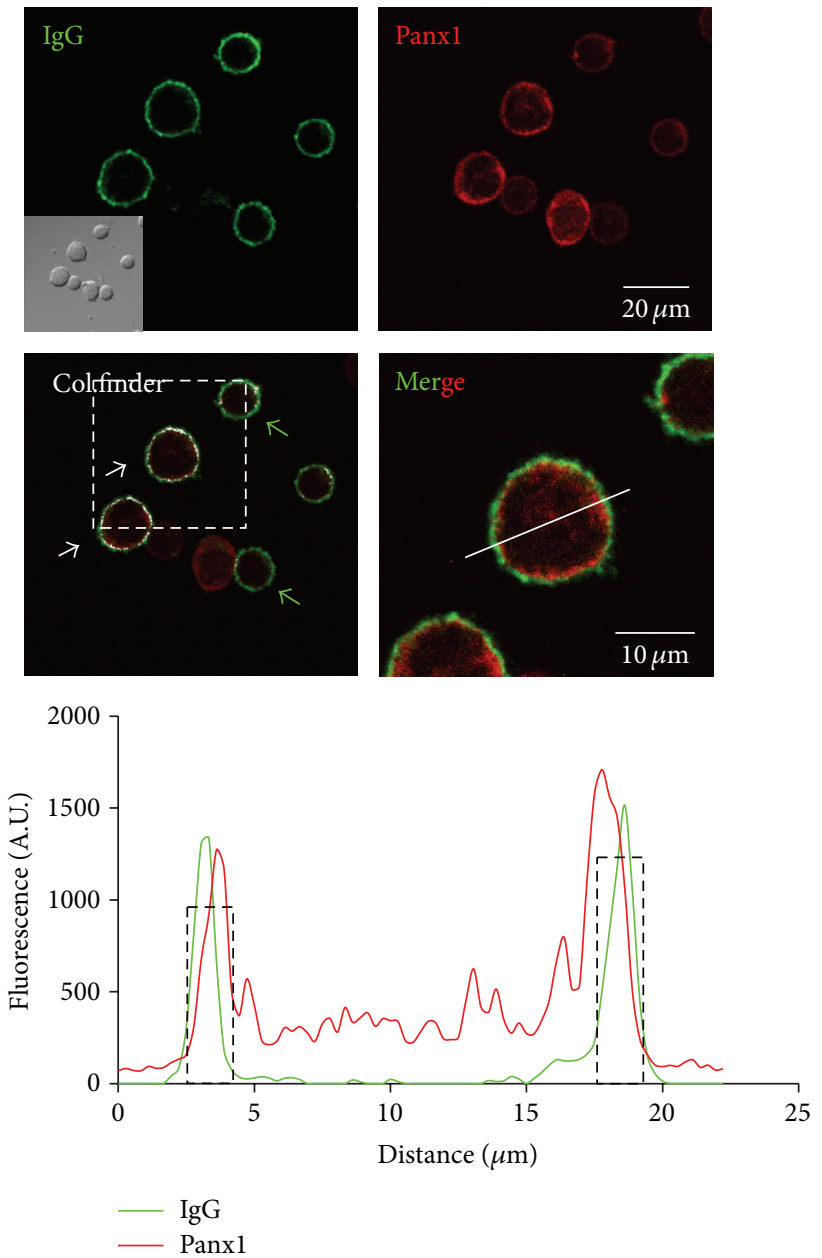

Figure 6: B cells present pannexinl at the cell surface. Confocal images (Olympus, FluoView FV1000) of immunofluorescence analysis of freshly isolated B cells fixed in ethanol (70\%). B cells were isolated from peripheral lymph nodes by positive selection from balb/c mice. Top left: B cells were identified with IgG (conjugated to FITC, green); the inset shows the bright field. Top right: pannexinl (Panxl) immunoreactivity (red, primary antibody: rabbit anti-Panxl antibody and secondary antibody goat anti-rabbit IgG conjugated to Cy3) is shown. Bar: $20 \mu \mathrm{m}$. Middle left: using ImageJ colocalization finder, it can be seen that Panxl colocalizes with IgG (white) at the cell surface in some B cells (white arrows). B cells with low or no colocalization are indicated (green arrows). Middle right: zoom and merge of IgG and Panxl labeling in a B cell denoted by a dotted square at middle left panel. The white line denotes the region used for the line scan. Bar: $10 \mu \mathrm{m}$. Bottom: ImageJ line scan analysis shows the fluorescence intensity of each channel through the white line in the middle of each cell. The peak coincidence (denoted by dotted squares) is an index of colocalization between the different fluorophores.

we showed that two polarizing cytokines (IFN- $\gamma$ and IL-6) induce $\mathrm{HC}$ activity, but in combination they have antagonistic effects. This last fact is very important because it suggests that Cx GJCs and HCs might be involved in Th polarization, and different $\mathrm{Cx}$ profiles could be associated with a different phenotype.

During T-cell activation, expression of GJCs and HCs mainly constituted by $\mathrm{Cx} 43$ contributes to T-cell proliferation $[81,82,231,242]$. In addition, it has been recently demonstrated that $\mathrm{T}$ cells also express functional Panx1 HCs during activation [243-246]. Indeed, GJCs are formed during T cellB cell interactions [231, 247], as well as between B cells [231, 247], promoting immunoglobulin secretion. Here, we show that Panxl is at the cell surface of B cell and might form HCs that might contribute to $\mathrm{B}$ cell activation. To produce high affinity antibodies, B cells must interact with FDCs, and GJCs contribute to this process (Figure 7) [92, 93].

In the peak of an immune response, lymphocytes should arrive at the affected tissue where GJCs are observed between $\mathrm{T}$ cells and endothelial cells (Figure 7) [248]. Also, Cx43 contributes to B cell spreading and adhesion $[230,232]$. Consequently, it is possible that $\mathrm{Cx} 43$ and GJCs might be involved in this process in vivo. Moreover, $\mathrm{Cx} 43$ contributes to the development of Tregs [241], which transfer cAMP through GJCs and inhibit T-cell activation during resolution of immune response or immune suppression by Tregs [12]. Interestingly, GJCs between Tregs and DCs prevent the development of contact hypersensitivity reactions mediated by CD8 T cells [15]. Modulation of immune responses using "educated" immune cells was recently used to prevent allergy 

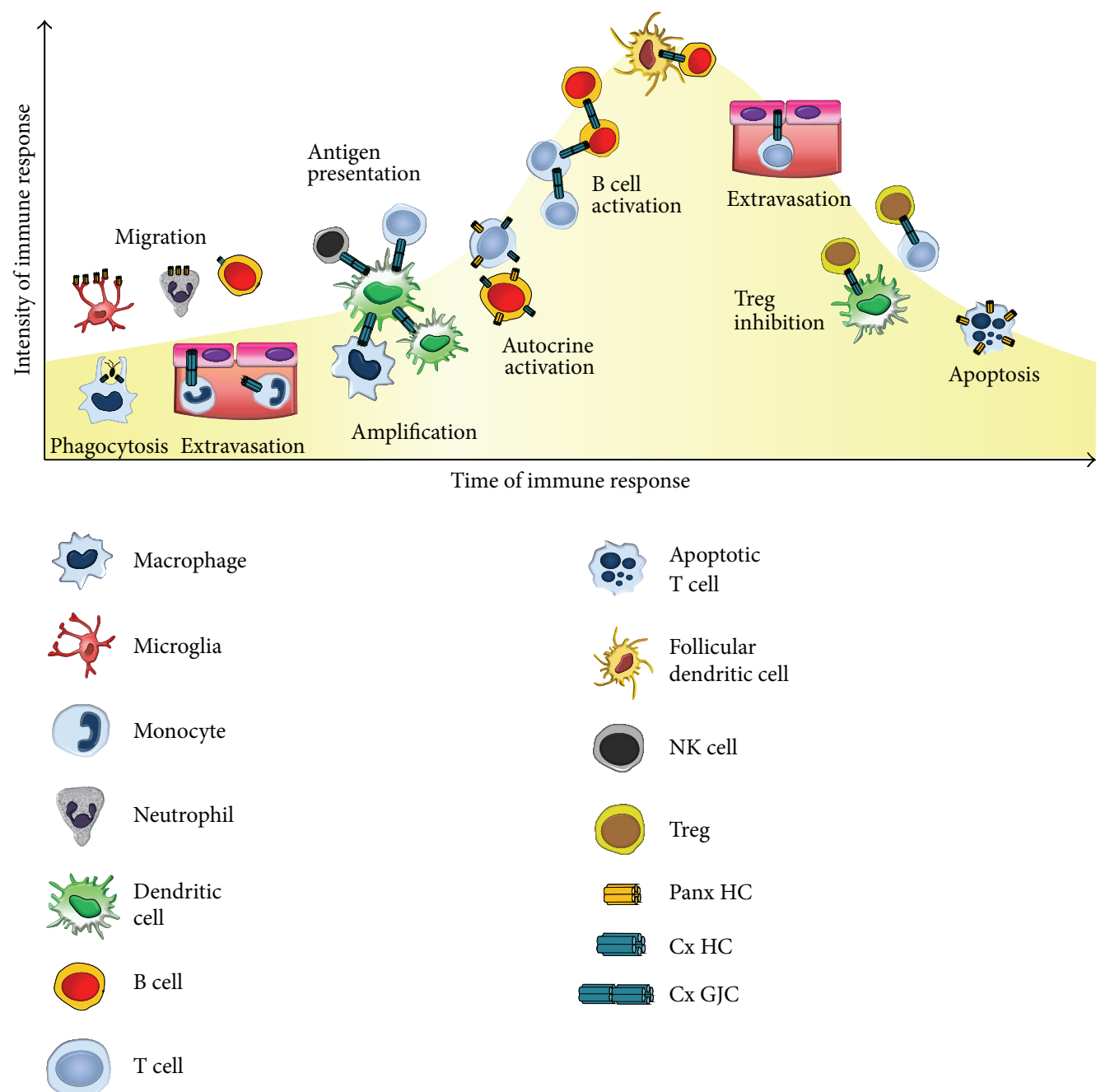

FIGURE 7: Scheme of different stages of classical immune response. The reported role for connexin- and pannexin-based channels is depicted in different immune cells functions as migration, antigen presentation, clonal expansion, and apoptosis.

reactions in mice. This effect was based on the generation of tolerogenic DCs after gap junctional communication with Tregs [249]. Another recent study showed that Tregs through GJCs are involved in controlling the HIV replication in $\mathrm{T}$ cells [250], opening an unexplored way to modulate the HIV infection.

We have summarized data showing that cytokines regulate both GJCs and HCs, which participate during most, if not all, steps of adaptive immune response. GJCs seem to be involved mainly in antigen presentation, whereas HCs are involved in functions such as migration or autocrine and paracrine activation. As presented here, during the lasts years a rising interest by immunologist in the field of cell-cell communication mediated by $\mathrm{Cx}$ - and Panx-based channels has driven many of the developments in the field. However, there is still much work to do because of more required technology transfer and collaboration between immunologists and "gap junctionologists." When the latter occurs, the GJC and $\mathrm{HC}$ regulation by cytokines might be used to provide an efficient immune response or to prevent or inhibit deleterious immune activation. Until recently, an important issue was the lack of specific tools to evaluate the role of GJC and
$\mathrm{HC}$ activity in vivo during the immune response. A first interesting approach was used with the reconstitution of a mice previously irradiated [251]. In this chimeric mouse, a slight effect was observed during inflammation, and no gene dosage was observed [251], suggesting the possibility of gene compensation. However, recently two different murine models were developed to study the role of $\mathrm{Cx} 43$ in $\mathrm{CD}_{11 c^{+}}$ cells, such as DCs and macrophages $[106,144]$. These studies used in vivo imaging and tissue analysis to show the relevance of gap junctional communication between APCs and APCs or between APCs and epithelial cells $[106,144]$. These tools have started a new age in the study of $\mathrm{Cx} 43$ in the immune response, even when a cell-specific K.O. for Panxs is still missing. However, compensation by other proteins might occur in these mice because the immune response should not rely only on the function of one protein, so the use of these tools should be analyzed in depth to avoid misinterpretations.

Finally, there is another possibility for the use of specific drug delivery to inhibit GJCs and HCs during in vivo responses, but the field of $\mathrm{Cx}$ - and Panx-based channel blockers is under development and mimetic peptides are not much specific [252]. However, new approaches are rising, 
such as with the antibody $\mathrm{Cx} 43^{(\mathrm{E} 2)}$ which inhibits $\mathrm{Cx} 43 \mathrm{HCs}$ $[253,254]$. After the development of these and other tools, the regulation by cytokines will open new possibilities to adjust the innate and adaptive immune responses.

\section{Conflict of Interests}

The authors declare that there is no conflict of interests regarding the publication of this paper.

\section{Acknowledgments}

This work was supported by Grants CONICYT 24100062 (to Pablo J. Sáez); FONDECYT Postdoctoral Fellowship 3130632 (to Adam Aguirre); FONDECYT 1111033, Chilean Science Millennium Institute P09-022 and FONDEF DO7I1086 (to Juan C. Sáez). The data of this work was presented by Pablo J. Sáez and Kenji F. Shoji as partial fulfillment for the requirements to obtain the degree of Ph.D. in biological sciences at the Pontificia Universidad Católica de Chile.

\section{References}

[1] F. D. Batista and M. L. Dustin, "Cell: cell interactions in the immune system," Immunological Reviews, vol. 251, no. 1, pp. 712, 2013.

[2] G. Gasteiger and A. Y. Rudensky, "Interactions between innate and adaptive lymphocytes," Nature Reviews Immunology, vol. 14, pp. 631-639, 2014.

[3] R. Debets and H. F. J. Savelkoul, "Cytokines as cellular communicators," Mediators of Inflammation, vol. 5, no. 6, pp. 417-423, 1996.

[4] A. Miyajima, T. Kitamura, N. Harada, T. Yokota, and K. Arai, "Cytokine receptors and signal transduction," Annual Review of Immunology, vol. 10, pp. 295-331, 1992.

[5] J. Xie, C. M. Tato, and M. M. Davis, "How the immune system talks to itself: the varied role of synapses," Immunological Reviews, vol. 251, no. 1, pp. 65-79, 2013.

[6] M. L. Kapsenberg, "Dendritic-cell control of pathogen-driven T-cell polarization," Nature Reviews Immunology, vol. 3, no. 12, pp. 984-993, 2003.

[7] R. Dantzer, J. C. O’Connor, G. G. Freund, R. W. Johnson, and K. W. Kelley, "From inflammation to sickness and depression: when the immune system subjugates the brain," Nature Reviews Neuroscience, vol. 9, no. 1, pp. 46-56, 2008.

[8] I. B. McInnes and G. Schett, "Cytokines in the pathogenesis of rheumatoid arthritis," Nature Reviews Immunology, vol. 7, no. 6, pp. 429-442, 2007.

[9] G. Dranoff, "Cytokines in cancer pathogenesis and cancer therapy," Nature Reviews Cancer, vol. 4, no. 1, pp. 11-22, 2004.

[10] A. Meager, "Cytokine regulation of cellular adhesion molecule expression in inflammation," Cytokine and Growth Factor Reviews, vol. 10, no. 1, pp. 27-39, 1999.

[11] V. Hornung, R. Hartamann, A. Ablasser, and K. P. Hopfner, "OAS proteins and cGAS: unifying concepts in sensing and responding to cytosolic nucleic acids," Nature Reviews Immunology, vol. 14, pp. 521-528, 2014.
[12] T. Bopp, C. Becker, M. Klein et al., "Cyclic adenosine monophosphate is a key component of regulatory $\mathrm{T}$ cellmediated suppression," The Journal of Experimental Medicine, vol. 204, no. 6, pp. 1303-1310, 2007.

[13] R. Elgueta, J. A. Tobar, K. F. Shoji et al., "Gap junctions at the dendritic cell-T cell interface are key elements for antigendependent T cell activation," The Journal of Immunology, vol. 183, no. 1, pp. 277-284, 2009.

[14] J. Neijssen, B. Pang, and J. Neefjes, "Gap junction-mediated intercellular communication in the immune system," Progress in Biophysics and Molecular Biology, vol. 94, no. 1-2, pp. 207-218, 2007.

[15] S. Ring, S. Karakhanova, T. Johnson, A. H. Enk, and K. Mahnke, "Gap junctions between regulatory T cells and dendritic cells prevent sensitization of $\mathrm{CD}^{+} \mathrm{T}$ cells," Journal of Allergy and Clinical Immunology, vol. 125, no. 1, pp. 237.e7-246.e7, 2010.

[16] F. Saccheri, C. Pozzi, F. Avogadri et al., "Bacteria-induced gap junctions in tumors favor antigen cross-presentation and antitumor immunity," Science Translational Medicine, vol. 2, no. 44, Article ID 44ra57, 2010.

[17] J. C. Sáez, R. Araya, M. C. Brañes et al., "Chapter 25: gap junctions in inflammatory responses: connexins, regulation and possible functional roles," in Current Topics in Membranes, vol. 49 of Gap Junctions-Molecular Basis of Cell Communication in Health and Disease, pp. 555-579, 2000.

[18] J. C. Sáez, V. M. Berthoud, M. C. Brañes, A. D. Martínez, and E. C. Beyer, "Plasma membrane channels formed by connexins: their regulation and functions," Physiological Reviews, vol. 83, pp. 1359-1400, 2003.

[19] C. D'Hondt, J. Iyyathurai, M. Vinken et al., "Regulation of connexin- and pannexin-based channels by post-translational modifications," Biology of the Cell, vol. 105, no. 9, pp. 373-398, 2013.

[20] C. D'hondt, R. Ponsaerts, H. de Smedt, G. Bultynck, and B. Himpens, "Pannexins, distant relatives of the connexin family with specific cellular functions?” BioEssays, vol. 31, no. 9, pp. 953-974, 2009.

[21] A. Ablasser, J. L. Schmid-Burgk, I. Hemmerling et al., "Cell intrinsic immunity spreads to bystander cells via the intercellular transfer of cGAMP," Nature, vol. 503, pp. 530-534, 2013.

[22] A. L. Harris, "Connexin channel permeability to cytoplasmic molecules," Progress in Biophysics and Molecular Biology, vol. 94, no. 1-2, pp. 120-143, 2007.

[23] M. Katakowski, B. Buller, X. Wang, T. Rogers, and M. Chopp, "Functional microRNA is transferred between glioma cells," Cancer Research, vol. 70, no. 21, pp. 8259-8263, 2010.

[24] A. Mendoza-Naranjo, P. J. Saéz, C. C. Johansson et al., "Functional gap junctions facilitate melanoma antigen transfer and cross-presentation between human dendritic cells," The Journal of Immunology, vol. 178, no. 11, pp. 6949-6957, 2007.

[25] J. Neijssen, C. Herberts, J. W. Drijfhout, E. Reits, L. Janssen, and J. Neefjes, "Cross-presentation by intercellular peptide transfer through gap junctions," Nature, vol. 434, no. 7029, pp. 83-88, 2005.

[26] O. Tour, S. R. Adams, R. A. Kerr et al., "Calcium Green FlAsH as a genetically targeted small-molecule calcium indicator," Nature Chemical Biology, vol. 3, no. 7, pp. 423-431, 2007.

[27] R. Bruzzone, S. G. Hormuzdi, M. T. Barbe, A. Herb, and H. Monyer, "Pannexins, a family of gap junction proteins expressed in brain," Proceedings of the National Academy of Sciences of the United States of America, vol. 100, no. 23, pp. 13644-13649, 2003. 
[28] F. Vanden Abeele, G. Bidaux, D. Gordienko et al., "Functional implications of calcium permeability of the channel formed by pannexin 1," The Journal of Cell Biology, vol. 174, no. 4, pp. 535546, 2006.

[29] M. Ishikawa, T. Iwamoto, T. Nakamura, A. Doyle, S. Fukumoto, and Y. Yamada, "Pannexin 3 functions as an ER Ca ${ }^{2+}$ channel, hemichannel, and gap junction to promote osteoblast differentiation," Journal of Cell Biology, vol. 193, no. 7, pp. 1257-1274, 2011.

[30] G. E. Sosinsky, D. Boassa, R. Dermietzel et al., "Pannexin channels are not gap junction hemichannels," Channels, vol. 5, no. 3, pp. 193-197, 2011.

[31] C. Ambrosi, O. Gassmann, J. N. Pranskevich et al., "Pannexin1 and pannexin2 channels show quaternary similarities to connexons and different oligomerization numbers from each other," The Journal of Biological Chemistry, vol. 285, no. 32, pp. 24420-24431, 2010.

[32] R. A. Romanov, M. F. Bystrova, O. A. Rogachevskaya, V. B. Sadovnikov, V. I. Shestopalov, and S. S. Kolesnikov, "The ATP permeability of pannexin 1 channels in a heterologous system and in mammalian taste cells is dispensable," Journal of Cell Science, vol. 125, no. 22, pp. 5514-5523, 2012.

[33] L. A. Cea, B. A. Cisterna, C. Puebla, M. Frank, and X. F. Figueroa, "De novo expression of connexin hemichannels in denervated fast skeletal muscles leads to atrophy," Proceedings of the National Academy of Sciences of the United States of America, vol. 110, pp. 16229-16234, 2013.

[34] W. G. Junger, "Immune cell regulation by autocrine purinergic signalling," Nature Reviews Immunology, vol. 11, no. 3, pp. 201212, 2011.

[35] A. Baroja-Mazo, M. Barberà-Cremades, and P. Pelegrín, "The participation of plasma membrane hemichannels to purinergic signaling," Biochimica et Biophysica Acta: Biomembranes, vol. 1828, no. 1, pp. 79-93, 2013.

[36] E. Decrock, M. Vinken, M. Bol et al., "Calcium and connexinbased intercellular communication, a deadly catch?" Cell Calcium, vol. 50, no. 3, pp. 310-321, 2011.

[37] P. Pelegrin and A. Surprenant, "The P2X7 receptor-pannexin connection to dye uptake and IL-1 $\beta$ release," Purinergic Signalling, vol. 5, no. 2, pp. 129-137, 2009.

[38] J. E. Contreras, H. A. Sánchez, E. A. Eugenin et al., "Metabolic inhibition induces opening of unapposed connexin 43 gap junction hemichannels and reduces gap junctional communication in cortical astrocytes in culture," Proceedings of the National Academy of Sciences of the United States of America, vol. 99, no. 1, pp. 495-500, 2002.

[39] P. Pelegrin and A. Surprenant, "Pannexin-1 mediates large pore formation and interleukin- $1 \beta$ release by the ATP-gated P2X7 receptor," EMBO Journal, vol. 25, no. 21, pp. 5071-5082, 2006.

[40] K. A. Schalper, N. Palacios-Prado, J. A. Orellana, and J. C. Sáez, "Currently used methods for identification and characterization of hemichannels," Cell Communication and Adhesion, vol. 15, no. 1-2, pp. 207-218, 2008.

[41] A. Koulakoff, X. Mei, J. A. Orellana, J. C. Sáez, and C. Giaume, "Glial connexin expression and function in the context of Alzheimer's disease," Biochimica et Biophysica ActaBiomembranes, vol. 1818, no. 8, pp. 2048-2057, 2012.

[42] J. C. Sáez, M. C. Brañes, L. A. Corvalán et al., "Gap junctions in cells of the immune system: structure, regulation and possible functional roles," Brazilian Journal Of Medical and Biological Research, vol. 33, pp. 447-455, 2000.
[43] J. D. Robertson, "The occurrence of a subunit pattern in the unit membranes of club endings in mauthner cell synapses in goldfish brains," Journal of Cell Biology, vol. 19, pp. 201-221, 1963.

[44] J. P. Revel, A. G. Yee, and A. J. Hudspeth, "Gap junctions between electrotonically coupled cells in tissue culture and in brown fat," Proceedings of the National Academy of Sciences of the United States of America, vol. 68, no. 12, pp. 2924-2927, 1971.

[45] J. P. Revel and M. J. Karnovsky, "Hexagonal array of subunits in intercellular junctions of the mouse heart and liver," The Journal of Cell Biology, vol. 33, no. 3, pp. C7-C12, 1967.

[46] G. D. Pappas, Y. Asada, and M. V. Bennett, "Morphological correlates of increased coupling resistance at an electrotonic synapse," Journal of Cell Biology, vol. 49, no. 1, pp. 173-188, 1971.

[47] L. Barr, M. M. Dewey, and W. Berger, "Propagation of action potentials and the structure of the nexus in cardiac muscle," The Journal of General Physiology, vol. 48, pp. 797-823, 1965.

[48] I. Simpson, B. Rose, and W. R. Loewenstein, "Size limit of molecules permeating the junctional membrane channels," Science, vol. 195, no. 4275, pp. 294-296, 1977.

[49] J. C. Sáez, J. A. Connor, D. C. Spray, and M. V. L. Bennett, "Hepatocyte gap junctions are permeable to the second messenger, inositol 1,4,5-trisphosphate, and to calcium ions," Proceedings of the National Academy of Sciences of the United States of America, vol. 86, no. 8, pp. 2708-2712, 1989.

[50] R. W. Tsien and R. Weingart, "Inotropic effect of cyclic AMP in calf ventricular muscle studied by a cut end method," Journal of Physiology, vol. 260, no. 1, pp. 117-141, 1976.

[51] C. U. Brand, T. Hunziker, T. Schaffner, A. Limat, H. A. Gerber, and L. R. Braathen, "Activated immunocompetent cells in human skin lymph derived from irritant contact dermatitis: an immunomorphological study," The British Journal of Dermatology, vol. 132, no. 1, pp. 39-45, 1995.

[52] M. Concha, A. Vidal, G. Garces, C. D. Figueroa, and I. Caorsi, "Physical interaction between Langerhans cells and Tlymphocytes during antigen presentation in vitro," Journal of Investigative Dermatology, vol. 100, no. 4, pp. 429-434, 1993.

[53] V. Valiunas, Y. Y. Polosina, H. Miller et al., "Connexin-specific cell-to-cell transfer of short interfering RNA by gap junctions," Journal of Physiology, vol. 568, no. 2, pp. 459-468, 2005.

[54] E. Tsitsiou and M. A. Lindsay, "microRNAs and the immune response," Current Opinion in Pharmacology, vol. 9, no. 4, pp. 514-520, 2009.

[55] A. Aucher, D. Rudnicka, and D. M. Davis, "MicroRNAs transfer from human macrophages to hepato-carcinoma cells and inhibit proliferation," The Journal of Immunology, vol. 191, pp. 6250-6260, 2013.

[56] M. Vig and J. Kinet, "Calcium signaling in immune cells," Nature Immunology, vol. 10, no. 1, pp. 21-27, 2009.

[57] D. G. Gossman and H.-B. Zhao, "Hemichannel-mediated inositol 1,4,5-trisphosphate $\left(\mathrm{IP}_{3}\right)$ release in the cochlea: a novel mechanism of IP3 intercellular signaling," Cell Communication \& Adhesion, vol. 15, no. 4, pp. 305-315, 2008.

[58] K. Braet, W. Vandamme, P. E. M. Martin, W. H. Evans, and L. Leybaert, "Photoliberating inositol-1,4,5-trisphosphate triggers ATP release that is blocked by the connexin mimetic peptide gap 26," Cell Calcium, vol. 33, no. 1, pp. 37-48, 2003.

[59] A. T. Miller, P. P. Chamberlain, and M. P. Cooke, "Beyond IP3: roles for higher order inositol phosphates in immune cell signaling," Cell Cycle, vol. 7, no. 4, pp. 463-467, 2008. 
[60] W. Yang, M. K. Nurbaeva, E. Schmid et al., "Akt2- and ETS1dependent IP3 receptor 2 expression in dendritic cell migration," Cellular Physiology and Biochemistry, vol. 33, pp. 222-236, 2014.

[61] A. Mendoza-Naranjo, G. Bouma, C. Pereda et al., "Functional gap junctions accumulate at the immunological synapse and contribute to T cell activation," Journal of Immunology, vol. 187, no. 6, pp. 3121-3132, 2011.

[62] H. A. Sánchez, J. A. Orellana, V. K. Verselis, and J. C. Sáez, "Metabolic inhibition increases activity of connexin-32 hemichannels permeable to Ca2+ in transfected HeLa cells," The American Journal of Physiology-Cell Physiology, vol. 297, no. 3, pp. C665-C678, 2009.

[63] M. C. Fiori, V. Figueroa, M. E. Zoghbi, J. C. Saéz, L. Reuss, and G. A. Altenberg, "Permeation of calcium through purified connexin 26 hemichannels," The Journal of Biological Chemistry, vol. 287, no. 48, pp. 40826-40834, 2012.

[64] V. Figueroa, P. J. Sáez, J. D. Salas et al., "Linoleic acid induces opening of connexin26 hemichannels through a PI3K/Akt/Ca ${ }^{2+}$-dependent pathway," Biochimica et Biophysica Acta, vol. 1828, no. 3, pp. 1169-1179, 2013.

[65] M. De Bock, N. Wang, M. Bol et al., "Connexin 43 hemichannels contribute to cytoplasmic $\mathrm{Ca}^{2+}$ oscillations by providing a bimodal $\mathrm{Ca}^{2+}$-dependent $\mathrm{Ca}^{2+}$ entry pathway," Journal of Biological Chemistry, vol. 287, no. 15, pp. 12250-12266, 2012.

[66] K. A. Schalper, H. A. Sánchez, S. C. Lee, G. A. Altenberg, M. H. Nathanson, and J. C. Sáez, "Connexin 43 hemichannels mediate the $\mathrm{Ca}^{2+}$ influx induced by extracellular alkalinization," The American Journal of Physiology: Cell Physiology, vol. 299, no. 6, pp. C1504-C1515, 2010.

[67] H. A. Sánchez, G. Meşe, M. Srinivas, T. W. White, and V. K. Verselis, "Differentially altered $\mathrm{Ca} 2+$ regulation and $\mathrm{Ca} 2+$ permeability in $\mathrm{Cx} 26$ hemichannels formed by the A40V and G45E mutations that cause keratitis ichthyosis deafness syndrome," Journal of General Physiology, vol. 136, no. 1, pp. 4762, 2010.

[68] F. Malavasi, S. Deaglio, A. Funaro et al., "Evolution and function of the ADP ribosyl cyclase/CD38 gene family in physiology and pathology," Physiological Reviews, vol. 88, no. 3, pp. 841-886, 2008.

[69] S. Bruzzone, L. Franco, L. Guida et al., "A self-restricted CD38-connexin 43 cross-talk affects NAD+ and cyclic ADPribose metabolism and regulates intracellular calcium in 3T3 fibroblasts," Journal of Biological Chemistry, vol. 276, no. 51, pp. 48300-48308, 2001.

[70] S. Bruzzone, L. Guida, E. Zocchi, L. Franco, and A. de Flora, "Connexin 43 hemi channels mediate Ca2+-regulated transmembrane NAD+ fluxes in intact cells," The FASEB Journal, vol. 15, no. 1, pp. 10-12, 2001.

[71] X. J. Xu, M. Boumechache, L. E. Robinson et al., "Splice variants of the P2X7 receptor reveal differential agonist dependence and functional coupling with pannexin-1," Journal of Cell Science, vol. 125, no. 16, pp. 3776-3789, 2012.

[72] E. Song, S. Rah, Y. Lee et al., "Connexin-43 hemichannels mediate cyclic ADP-ribose generation and its $\mathrm{Ca}^{2+}$-mobilizing activity by $\mathrm{NAD}^{+} /$cyclic ADP-ribose transport," The Journal of Biological Chemistry, vol. 286, no. 52, pp. 44480-44490, 2011.

[73] Y. Ma, W. Cao, L. Wang et al., "Basal CD38/cyclic ADP-ribosedependent signaling mediates ATP release and survival of microglia by modulating connexin 43 hemichannels," Glia, vol. 62, no. 6, pp. 943-955, 2014.
[74] M. J. L. Bours, E. L. R. Swennen, F. di Virgilio, B. N. Cronstein, and P. C. Dagnelie, "Adenosine 5/-triphosphate and adenosine as endogenous signaling molecules in immunity and inflammation," Pharmacology and Therapeutics, vol. 112, no. 2, pp. 358404, 2006.

[75] H. Kono and K. L. Rock, "How dying cells alert the immune system to danger," Nature Reviews Immunology, vol. 8, no. 4, pp. 279-289, 2008.

[76] N. Wang, M. de Bock, E. Decrock et al., "Paracrine signaling through plasma membrane hemichannels," Biochimica et Biophysica Acta-Biomembranes, vol. 1828, no. 1, pp. 35-50, 2013.

[77] M. Rodriguez, E. Domingo, C. Municio, Y. Alvarez, and E. Hugo, "Polarization of the innate immune response by prostaglandin E2: a puzzle of receptors and signals," Molecular Pharmacology, vol. 85, pp. 187-197, 2014.

[78] B. Cheng, Y. Kato, S. Zhao et al., "PGE2 is essential for gap junction-mediated Intercellular communication between osteocyte-like MLO-Y4 cells in response to mechanical strain," Endocrinology, vol. 142, no. 8, pp. 3464-3473, 2001.

[79] J. X. Jiang and P. P. Cherian, "Hemichannels formed by connexin 43 play an important role in the release of protaglandin E2 by osteocytes in response to mechanical strain," Cell Communication and Adhesion, vol. 10, no. 4-6, pp. 259-264, 2003.

[80] M. Barbera-Cremades, A. Baroja-Mazo, A. I. Gomez, F. Machado, F. Di Virgilio, and P. Pelegriń, "P2X7 receptorstimulation causes fever via PGE2 and IL-1 $\beta$ release," The FASEB Journal, vol. 26, no. 7, pp. 2951-2962, 2012.

[81] D. F. Hülser and J. H. Peters, "Intercellular communication in phytohemagglutinin-induced lymphocyte agglutinates," European Journal of Immunology, vol. 1, no. 6, pp. 494-495, 1971.

[82] D. F. Hülser and J. H. Peters, "Contact cooperation in stimulated lymphocytes. II. Electrophysiological investigations on intercellular communication," Experimental Cell Research, vol. 74, no. 2, pp. 319-326, 1972.

[83] E. A. Eugenín, "Role of Connexin/Pannexin containing channels in infectious diseases," FEBS Letters, vol. 588, no. 8, pp. 1389-1395, 2014.

[84] D. Gao, J. Wu, Y. Wu et al., "Cyclic GMP-AMP synthase is an innate immune sensor of HIV and other retroviruses," Science, vol. 341, no. 6148, pp. 903-906, 2013.

[85] X. Lahaye, T. Satoh, M. Gentili et al., "The capsids of HIV-1 and HIV-2 determine immune detection of the viral cDNA by the innate sensor cGAS in dendritic cells," Immunity, vol. 39, no. 6, pp. 1132-1142, 2013.

[86] L. A. Corvalán, R. Araya, M. C. Brañes et al., "Injury of skeletal muscle and specific cytokines induce the expression of gap junction channels in mouse dendritic cells," Journal of Cellular Physiology, vol. 211, pp. 649-660, 2007.

[87] H. Matsue, J. Yao, K. Matsue et al., "Gap junction-mediated intercellular communication between dendritic cells (DCs) is required for effective activation of DCs," The Journal of Immunology, vol. 176, no. 1, pp. 181-190, 2006.

[88] M. Porvaznik and T. J. MacVittie, "Detection of gap junctions between the progeny of a canine macrophage colony-forming cell in vitro," Journal of Cell Biology, vol. 82, no. 2, pp. 555-564, 1979.

[89] J. A. Levy, R. M. Weiss, E. R. Dirksen, and M. R. Rosen, "Possible communication between murine macrophages oriented in linear chains in tissue culture," Experimental Cell Research, vol. 103, no. 2, pp. 375-385, 1976. 
[90] M. Concha, C. D. Figueroa, and I. Caorsi, "Ultrastructural characteristics of the contact zones between Langerhans cells and lymphocytes," Journal of Pathology, vol. 156, no. 1, pp. 2936, 1988.

[91] T. Krenacs and M. Rosendaal, "Immunohistological detection of gap junctions in human lymphoid tissue: connexin 43 in follicular dendritic and lymphoendothelial cells," Journal of Histochemistry and Cytochemistry, vol. 43, no. 11, pp. 1125-1137, 1995.

[92] T. Krenacs and M. Rosendaal, "Gap-junction communication pathways in germinal center reactions," Developmental Immunology, vol. 6, no. 1-2, pp. 111-118, 1998.

[93] T. Krenacs, M. Van Dartel, E. Lindhout, and M. Rosendaal, "Direct cell/cell communication in the lymphoid germinal center: connexin43 gap junctions functionally couple follicular dendritic cells to each other and to B lymphocytes," European Journal of Immunology, vol. 27, no. 6, pp. 1489-1497, 1997.

[94] L. A. Alves, R. Coutinho-Silva, P. M. Persechini, D. C. Spray, W. Savino, and A. C. Campos de Carvalho, "Are there functional gap junctions or junctional hemichannels in macrophages?" Blood, vol. 88, no. 1, pp. 328-334, 1996.

[95] J. A. Orellana, P. J. Sáez, K. F. Shoji et al., "Modulation of brain hemichannels and gap junction channels by pro-inflammatory agents and their possible role in neurodegeneration," Antioxidants and Redox Signaling, vol. 11, no. 2, pp. 369-399, 2009.

[96] P. J. Sáez, K. F. Shoji, M. A. Retamal et al., "ATP is required and advances cytokine-induced gap junction formation in microglia in vitro," Mediators of Inflammation, vol. 2013, Article ID 216402, 16 pages, 2013.

[97] R. M. Steinman and Z. A. Cohn, "Identification of a novel cell type in peripheral lymphoid organs of mice. I. Morphology, quantitation, tissue distribution," The Journal of Experimental Medicine, vol. 137, no. 5, pp. 1142-1162, 1973.

[98] K. Liu and M. C. Nussenzweig, "Origin and development of dendritic cells," Immunological Reviews, vol. 234, no. 1, pp. 4554, 2010.

[99] R. Sluyter and J. S. Wiley, "Extracellular adenosine 5/triphosphate induces a loss of CD23 from human dendritic cells via activation of $\mathrm{P}_{2} \mathrm{X}_{7}$ receptors," International Immunology, vol. 14, no. 12, pp. 1415-1421, 2002.

[100] O. K. Nihei, A. C. C. de Carvalho, W. Savino, and L. A. Alves, "Pharmacologic properties of $\mathrm{P}_{2 Z} / \mathrm{P} 2 \mathrm{X}_{7}$ receptor characterized in murine dendritic cells: role on the induction of apoptosis," Blood, vol. 96, no. 3, pp. 996-1005, 2000.

[101] R. Coutinho-Silva, P. M. Persechini, R. Da Cunha Bisaggio et al., "P(2Z)/P2X7 receptor-dependent apoptosis of dendritic cells," The American Journal of Physiology-Cell Physiology, vol. 276, no. 5, pp. C1139-C1147, 1999.

[102] J. G. Georgiou, K. K. Skarratt, S. J. Fuller et al., "Human epidermal and monocyte-derived langerhans cells express functional P2X7 receptors," Journal of Investigative Dermatology, vol. 125, no. 3, pp. 482-490, 2005.

[103] Y. Kurashima, T. Amiya, T. Nochi et al., "Extracellular ATP mediates mast cell-dependent intestinal inflammation through P2X7 purinoceptors," Nature Communications, vol. 3, article 1034, 2012.

[104] V. I. Shestopalov and Y. Panchin, "Pannexins and gap junction protein diversity," Cellular and Molecular Life Sciences, vol. 65, no. 3, pp. 376-394, 2008.

[105] Y. He, L. Franchi, and G. Núñez, “TLR agonists stimulate Nlrp3dependent IL-1 $\beta$ production independently of the purinergic
P2X7 receptor in dendritic cells and in vivo," Journal of Immunology, vol. 190, no. 1, pp. 334-339, 2013.

[106] E. Mazzini, L. Massimiliano, G. Penna, and M. Rescigno, "Oral tolerance can be established via gap junction transfer of fed antigens from $\mathrm{CX}_{3} \mathrm{CR}^{+}$macrophages to $\mathrm{CD}_{103}{ }^{+}$dendritic cells," Immunity, vol. 40, no. 2, pp. 248-261, 2014.

[107] A. Tittarelli, A. Mendoza-Naranjo, M. Farias et al., "Gap junction intercellular communications regulate NK cell activation and modulate NK cytotoxic capacity," Journal of Immunology, vol. 192, pp. 1313-1319, 2014.

[108] S. C. Zimmerli, F. Masson, J. Cancela, P. Meda, and C. Hauser, "Cutting edge: lack of evidence for connexin-43 expression in human epidermal langerhans cells," The Journal of Immunology, vol. 179, no. 7, pp. 4318-4321, 2007.

[109] L. S. Deluca and J. L. Gommerman, "Fine-tuning of dendritic cell biology by the TNF superfamily," Nature Reviews Immunology, vol. 12, no. 5, pp. 339-351, 2012.

[110] J. E. Sims and D. E. Smith, "The IL-1 family: regulators of immunity," Nature Reviews Immunology, vol. 10, no. 2, pp. 89102, 2010.

[111] I. Fricke, D. Mitchell, J. Mittelstädt et al., "Mycobacteria induce IFN- $\gamma$ production in human dendritic cells via triggering of TLR2," The Journal of Immunology, vol. 176, no. 9, pp. 5173-5182, 2006.

[112] D. M. Frucht, T. Fukao, C. Bogdan, H. Schindler, J. J. O’Shea, and S. Koyasu, "IFN- $\gamma$ production by antigen-presenting cells: mechanisms emerge," Trends in Immunology, vol. 22, no. 10, pp. 556-560, 2001.

[113] E. M. Coccia, "IFN regulation and functions in myeloid dendritic cells," Cytokine and Growth Factor Reviews, vol. 19, no. 1, pp. 21-32, 2008.

[114] L. C. Platanias, "Mechanisms of type-I- and type-II-interferonmediated signalling," Nature Reviews Immunology, vol. 5, no. 5, pp. 375-386, 2005.

[115] T. Hirano, K. Yasukawa, H. Harada et al., "Complementary DNA for a novel human interleukin (BSF-2) that induces B lymphocytes to produce immunoglobulin," Nature, vol. 324, no. 6092, pp. 73-76, 1986.

[116] A. Kimura and T. Kishimoto, "IL-6: regulator of Treg/Th17 balance," European Journal of Immunology, vol. 40, no. 7, pp. 1830-1835, 2010.

[117] M. F. Neurath and S. Finotto, "IL-6 signaling in autoimmunity, chronic inflammation and inflammation-associated cancer," Cytokine and Growth Factor Reviews, vol. 22, no. 2, pp. 83-89, 2011.

[118] B. K. Pedersen, "IL-6 signalling in exercise and disease," Biochemical Society Transactions, vol. 35, no. 5, pp. 1295-1297, 2007.

[119] Z. Xing, J. Gauldie, G. Cox et al., "IL-6 is an antiinflammatory cytokine required for controlling local or systemic acute inflammatory responses," Journal of Clinical Investigation, vol. 101, no. 2, pp. 311-320, 1998.

[120] S. J. Park, T. Nakagawa, H. Kitamura et al., "IL-6 regulates in vivo dendritic cell differentiation through STAT3 activation," Journal of Immunology, vol. 173, no. 6, pp. 3844-3854, 2004.

[121] A. Yoshimura, T. Naka, and M. Kubo, "SOCS proteins, cytokine signalling and immune regulation," Nature Reviews Immunology, vol. 7, no. 6, pp. 454-465, 2007.

[122] P. Langerhans, "Ueber die Nerven der menschlichen Haut," Archiv für Pathologische Anatomie und Physiologie und für Klinische Medicin, vol. 44, no. 2-3, pp. 325-337, 1868. 
[123] G. Stingl, K. Tamaki, and S. I. Katz, "Origin and function of epidermal Langerhans cells," Immunological Reviews, vol. 53, pp. 149-174, 1980.

[124] T. Hieronymus, M. Zenke, J. H. Baek, and K. Sere, “The clash of Langerhans cell homeostasis in skin: should I stay or should I go?" Seminars in Cell \& Developmental Biology, 2014.

[125] L. G. Ng, A. Hsu, M. A. Mandell et al., "Migratory dermal dendritic cells act as rapid sensors of protozoan parasites," PLoS Pathogens, vol. 4, no. 11, p. e1000222, 2008.

[126] J. Banchereau, L. Thompson-Snipes, S. Zurawski et al., "The differential production of cytokines by human Langerhans cells and dermal CD14 + DCs controls CTL priming," Blood, vol. 119, no. 24, pp. 5742-5749, 2012.

[127] R. E. Hunger, P. A. Sieling, M. T. Ochoa et al., "Langerhans cells utilize CDla and langerin to efficiently present nonpeptide antigens to T cells," Journal of Clinical Investigation, vol. 113, no. 5, pp. 701-708, 2004.

[128] N. Romani, A. Lenz, H. Glassel et al., "Cultured human Langerhans cells resemble lymphoid dendritic cells in phenotype and function," Journal of Investigative Dermatology, vol. 93, no. 5, pp. 600-609, 1989.

[129] M. Merad, F. Ginhoux, and M. Collin, "Origin, homeostasis and function of Langerhans cells and other langerin-expressing dendritic cells," Nature Reviews Immunology, vol. 8, no. 12, pp. 935-947, 2008.

[130] N. Romani, P. M. Brunner, and G. Stingl, "Changing views of the role of langerhans cells," Journal of Investigative Dermatology, vol. 132, no. 3, pp. 872-881, 2012.

[131] S. J. Celetti, K. N. Cowan, S. Penuela, Q. Shao, J. Churko, and D. W. Laird, "Implications of pannexin 1 and pannexin 3 for keratinocyte differentiation," Journal of Cell Science, vol. 123, no. 8, pp. 1363-1372, 2010.

[132] J. N. S. N. Tran, A. Pupovac, R. M. Taylor, J. S. Wiley, S. N. Byrne, and R. Sluyter, "Murine epidermal Langerhans cells and keratinocytes express functional P2X7 receptors," Experimental Dermatology, vol. 19, no. 8, pp. e151-e157, 2010.

[133] R. D. Granstein, W. Ding, J. Huang et al., "Augmentation of cutaneous immune responses by $\mathrm{ATP} \gamma \mathrm{S}$ : purinergic agonists define a novel class of immunologic adjuvants," Journal of Immunology, vol. 174, no. 4, pp. 7725-7731, 2005.

[134] M. E. M. El Shikh and C. Pitzalis, "Follicular dendritic cells in health and disease," Frontiers in Immunology, vol. 3, article 292, 2012.

[135] F. D. Batista and N. E. Harwood, "The who, how and where of antigen presentation to B cells," Nature Reviews Immunology, vol. 9, no. 1, pp. 15-27, 2009.

[136] C. Shi and E. G. Pamer, "Monocyte recruitment during infection and inflammation," Nature Reviews Immunology, vol. 11, no. 11, pp. 762-774, 2011.

[137] S. Gordon and P. R. Taylor, "Monocyte and macrophage heterogeneity," Nature Reviews Immunology, vol. 5, no. 12, pp. 953-964, 2005.

[138] E. Asgari, G. Le Friec, H. Yamamoto et al., "C3a modulates ILlbeta secretion in human monocytes by regulating ATP efflux and subsequent NLRP3 inflammasome activation," Blood, vol. 122, pp. 3473-3481, 2013.

[139] B. Caillou, M. Talbot, U. Weyemi et al., "Tumor-Associated macrophages (TAMs) form an interconnected cellular supportive network in anaplastic thyroid carcinoma," PLoS ONE, vol. 6, no. 7, Article ID e22567, 2011.
[140] E. A. Eugenín, M. C. Brañes, J. W. Berman, and J. C. Sáez, “TNF$\alpha$ plus IFN- $\gamma$ induce connexin43 expression and formation of gap junctions between human monocytes/macrophages that enhance physiological responses," The Journal of Immunology, vol. 170, no. 3, pp. 1320-1328, 2003.

[141] P. I. Jara, M. P. Boric, and J. C. Sáez, "Leukocytes express connexin 43 after activation with lipopolysaccharide and appear to form gap junctions with endothelial cells after ischemiareperfusion," Proceedings of the National Academy of Sciences of the United States of America, vol. 92, no. 15, pp. 7011-7015, 1995.

[142] L. P. Véliz, F. G. González, B. R. Duling, J. C. Sáez, and M. P. Boric, "Functional role of gap junctions in cytokine-induced leukocyte adhesion to endothelium in vivo," The American Journal of Physiology-Heart and Circulatory Physiology, vol. 295, no. 3, pp. H1056-H1066, 2008.

[143] S. K. Wasseff and S. S. Scherer, "Activated microglia do not form functional gap junctions in vivo," Journal of Neuroimmunology, vol. 269, no. 1-2, pp. 90-93, 2014.

[144] K. Westphalen, G. A. Gusarova, M. N. Islam et al., "Sessile alveolar macrophages communicate with alveolar epithelium to modulate immunity," Nature, vol. 506, pp. 503-506, 2014.

[145] A. Bermudez-Fajardo, M. Ylihärsilä, W. H. Evans, A. C. Newby, and E. Oviedo-Orta, "CD4+ T lymphocyte subsets express connexin 43 and establish gap junction channel communication with macrophages in vitro," Journal of Leukocyte Biology, vol. 82, no. 3, pp. 608-612, 2007.

[146] D. Yuan, Q. Wang, D. Wu et al., "Monocyte-endothelial adhesion is modulated by $\mathrm{Cx} 43$-stimulated ATP release from monocytes," Biochemical and Biophysical Research Communications, vol. 420, no. 3, pp. 536-541, 2012.

[147] C. W. Wong, T. Christen, I. Roth et al., "Connexin37 protects against atherosclerosis by regulating monocyte adhesion," Nature Medicine, vol. 12, no. 8, pp. 950-954, 2006.

[148] B. J. Gu, W. Y. Zhang, L. J. Bendall, I. P. Chessell, G. N. Buell, and J. S. Wiley, "Expression of P2X(7) purinoceptors on human lymphocytes and monocytes: evidence for nonfunctional P2X7 receptors," American Journal of Physiology: Cell Physiology, vol. 279, no. 4, pp. C1189-C1197, 2000.

[149] S. R. Ali, A. M. Timmer, S. Bilgrami et al., "Anthrax toxin induces macrophage death by 38 MAPK inhibition but leads to inflammasome activation via ATP leakage," Immunity, vol. 35, no. 1, pp. 34-44, 2011.

[150] R. J. Anand, S. Dai, S. C. Gribar et al., "A role for connexin43 in macrophage phagocytosis and host survival after bacterial peritoneal infection," Journal of Immunology, vol. 181, no. 12, pp. 8534-8543, 2008.

[151] E. C. Beyer and T. H. Steinberg, "Evidence that the gap junction protein connexin-43 is the ATP-induced pore of mouse macrophages," The Journal of Biological Chemistry, vol. 266, no. 13, pp. 7971-7974, 1991.

[152] F. S. A. Fortes, I. L. Pecora, P. M. Persechini et al., "Modulation of intercellular communication in macrophages: possible interactions between GAP junctions and P2 receptors," Journal of Cell Science, vol. 117, no. 20, pp. 4717-4726, 2004.

[153] A. M. Glass, B. J. Wolf, K. M. Schneider, M. F. Princiotta, and S. M. Taffet, "Connexin 43 is dispensable for phagocytosis," Journal of Immunology, vol. 190, no. 9, pp. 4830-4835, 2013.

[154] M. M. Monick, A. B. Carter, P. K. Robeff, D. M. Flaherty, M. W. Peterson, and G. W. Hunninghake, "Lipopolysaccharide activates Akt in human alveolar macrophages resulting in nuclear accumulation and transcriptional activity of $\beta$-catenin," The Journal of Immunology, vol. 166, no. 7, pp. 4713-4720, 2001. 
[155] D. Polacek, R. Lal, M. V. Volin, and P. F. Davies, "Gap junctional communication between vascular cells: induction of connexin 43 messenger RNA in macrophage foam cells of atherosclerotic lesions," The American Journal of Pathology, vol. 142, no. 2, pp. 593-606, 1993.

[156] G. Ayna, D. V. Krysko, A. Kaczmarek, G. Petrovski, P. Vandenabeele, and L. Fésüs, "ATP release from dying autophagic cells and their phagocytosis are crucial for inflammasome activation in macrophages," PLoS ONE, vol. 7, no. 6, Article ID e40069, 2012.

[157] X. F. Figueroa, M. A. Lillo, P. S. Gaete, M. A. Riquelme, and J. C. Sáez, "Diffusion of nitric oxide across cell membranes of the vascular wall requires specific connexin-based channels," Neuropharmacology, vol. 75, pp. 471-478, 2013.

[158] R. J. Anand, S. Dai, C. Rippel et al., "Activated macrophages inhibit enterocyte gap junctions via the release of nitric oxide," American Journal of Physiology: Gastrointestinal and Liver Physiology, vol. 294, no. 1, pp. G109-G119, 2008.

[159] P. Pelegrin and A. Surprenant, "Pannexin-1 couples to maitotoxin- and nigericin-induced interleukin- $1 \beta$ release through a dye uptake-independent pathway," Journal of Biological Chemistry, vol. 282, no. 4, pp. 2386-2394, 2007.

[160] G. Lopez-Castejón, A. Baroja-Mazo, and P. Pelegrín, "Novel macrophage polarization model: from gene expression to identification of new anti-inflammatory molecules," Cellular and Molecular Life Sciences, vol. 68, no. 18, pp. 3095-3107, 2011.

[161] F. O. Martínez and S. Gordon, "The M1 and M2 paradigm of macrophage activation: time for reassessment," F1000Prime Reports, vol. 6, article 13, 2014.

[162] M. J. Kiel and S. J. Morrison, "Uncertainty in the niches that maintain haematopoietic stem cells," Nature Reviews Immunology, vol. 8, no. 4, pp. 290-301, 2008.

[163] A. W. Thomson and P. A. Knolle, "Antigen-presenting cell function in the tolerogenic liver environment," Nature Reviews Immunology, vol. 10, no. 11, pp. 753-766, 2010.

[164] K. Pulford and R. L. Souhami, "Cell division and giant cell formation in Kupffer cell cultures," Clinical and Experimental Immunology, vol. 42, no. 1, pp. 67-76, 1980.

[165] H. Ishibashi, M. Nakamura, A. Komori, K. Migita, and S. Shimoda, "Liver architecture, cell function, and disease," Seminars in Immunopathology, vol. 31, no. 3, pp. 399-409, 2009.

[166] L. Beattie, A. Peltan, A. Maroof et al., "Dynamic imaging of experimental Leishmania donovani-induced hepatic granulomas detects kupffer cell-restricted antigen presentation to antigen-specific CD8 T cells," PLoS Pathogens, vol. 6, no. 3, Article ID e1000805, 2010.

[167] P. A. Knolle and G. Gerken, "Local control of the immune response in the liver," Immunological Reviews, vol. 174, pp. 2134, 2000.

[168] E. A. Eugenín, H. E. González, H. A. Sanchez, M. C. Brañes, and J. C. Sáez, "Inflammatory conditions induce gap junctional communication between rat Kupffer cells both in vivo and in vitro," Cellular Immunology, vol. 247, pp. 103-110, 2007.

[169] H. E. González, E. A. Eugenín, and G. Garcés, "Regulation of hepatic connexins in cholestasis: possible involvement of Kupffer cells and inflammatory mediators," American Journal of Physiology: Gastrointestinal and Liver Physiology, vol. 282, pp. G991-G1001, 2002.

[170] H. Takayanagi, "Osteoimmunology: shared mechanisms and crosstalk between the immune and bone systems," Nature Reviews Immunology, vol. 7, no. 4, pp. 292-304, 2007.
[171] Z. S. Buchwald and R. Aurora, "Osteoclasts and CD8 T cells form a negative feedback loop that contributes to homeostasis of both the skeletal and immune systems," Clinical and Developmental Immunology, vol. 2013, Article ID 429373, 9 pages, 2013.

[172] N. Batra, R. Kar, and J. X. Jiang, "Gap junctions and hemichannels in signal transmission, function and development of bone," Biochimica et Biophysica Acta: Biomembranes, vol. 1818, no. 8, pp. 1909-1918, 2012.

[173] M. Watkins, S. K. Grimston, J. Y. Norris et al., "Osteoblast connexin 43 modulates skeletal architecture by regulating both arms of bone remodeling," Molecular Biology of the Cell, vol. 22, no. 8, pp. 1240-1251, 2011.

[174] S. Tsuchida, Y. Arai, T. Kishida et al., "Silencing the expression of connexin 43 decreases inflammation and joint destruction in experimental arthritis," Journal of Orthopaedic Research, vol. 31, no. 4, pp. 525-530, 2013.

[175] Y. Zhang, E. M. Paul, V. Sathyendra et al., "Enhanced osteoclastic resorption and responsiveness to mechanical load in gap junction deficient bone," PLoS ONE, vol. 6, no. 8, Article ID e23516, 2011.

[176] A. F. Schilling, S. Filke, T. Lange et al., "Gap junctional communication in human osteoclasts in vitro and in vivo," Journal of Cellular and Molecular Medicine, vol. 12, no. 6A, pp. 2497-2504, 2008.

[177] K. Herde, S. Hartmann, R. Brehm et al., "Connexin 43 expression of foreign body giant cells after implantation of nanoparticulate hydroxyapatite," Biomaterials, vol. 28, no. 33, pp. 4912-4921, 2007.

[178] S. F. Matemba, A. Lie, and M. Ransjö, "Regulation of osteoclastogenesis by gap junction communication," Journal of Cellular Biochemistry, vol. 99, no. 2, pp. 528-537, 2006.

[179] M. Ransjö, J. Sahli, and A. Lie, "Expression of connexin 43 mRNA in microisolated murine osteoclasts and regulation of bone resorption in vitro by gap junction inhibitors," Biochemical and Biophysical Research Communications, vol. 303, no. 4, pp. 1179-1185, 2003.

[180] J. Ilvesaro, P. Tavi, and J. Tuukkanen, "Connexin-mimetic peptide Gap 27 decreases osteoclastic activity," BMC Musculoskeletal Disorders, vol. 2, article 10, 2001.

[181] J. Ilvesaro, K. Väänänen, and J. Tuukkanen, "Bone-resorbing osteoclasts contain gap-junctional connexin-43," Journal of Bone and Mineral Research, vol. 15, no. 5, pp. 919-926, 2000.

[182] S. J. Jones, C. Gray, H. Sakamaki et al., "The incidence and size of gap junctions between the bone cells in rat calvaria," Anatomy and Embryology, vol. 187, no. 4, pp. 343-352, 1993.

[183] I. Lemaire, S. Falzoni, B. Zhang, P. Pellegatti, and F. di Virgilio, "The P2X7 receptor and pannexin-1 are both required for the promotion of multinucleated macrophages by the inflammatory cytokine GM-CSF," Journal of Immunology, vol. 187, no. 7, pp. 3878-3887, 2011.

[184] U. Hanisch, "Microglia as a source and target of cytokines," GLIA, vol. 40, no. 2, pp. 140-155, 2002.

[185] R. M. Ransohoff and V. H. Perry, "Microglial physiology: unique stimuli, specialized responses," Annual Review of Immunology, vol. 27, pp. 119-145, 2009.

[186] H. Kettenmann, U. K. Hanisch, M. Noda, and A. Verkhratsky, "Physiology of microglia," Physiological Reviews, vol. 91, no. 2, pp. 461-553, 2011.

[187] H. Takeuchi, S. Jin, J. Wang et al., "Tumor necrosis factor- $\alpha$ induces neurotoxicity via glutamate release from hemichannels of activated microglia in an autocrine manner," The Journal of Biological Chemistry, vol. 281, no. 30, pp. 21362-21368, 2006. 
[188] S. E. Samuels, J. B. Lipitz, J. Wang, G. Dahl, and K. J. Muller, "Arachidonic acid closes innexin/pannexin channels and thereby inhibits microglia cell movement to a nerve injury," Developmental Neurobiology, vol. 73, no. 8, pp. 621-631, 2013.

[189] J. A. Orellana, K. F. Shoji, V. Abudara et al., "Amyloid $\beta$-induced death in neurons involves glial and neuronal hemichannels," Journal of Neuroscience, vol. 31, no. 13, pp. 4962-4977, 2011.

[190] A. M. Fontainhas, M. Wang, K. J. Liang et al., "Microglial morphology and dynamic behavior is regulated by ionotropic glutamatergic and GABAergic neurotransmission," PLoS ONE, vol. 6, no. 1, Article ID e15973, 2011.

[191] D. Davalos, J. Grutzendler, G. Yang et al., "ATP mediates rapid microglial response to local brain injury in vivo," Nature Neuroscience, vol. 8, no. 6, pp. 752-758, 2005.

[192] S. B. Shaikh, B. Uy, A. Perera, and L. F. B. Nicholson, "AGEsRAGE mediated up-regulation of connexin 43 in activated human microglial CHME-5 cells," Neurochemistry International, vol. 60, no. 6, pp. 640-651, 2012.

[193] S. Garg, M. M. Syed, and T. Kielian, "Staphylococcus aureusderived peptidoglycan induces $\mathrm{Cx} 43$ expression and functional gap junction intercellular communication in microglia," Journal of Neurochemistry, vol. 95, no. 2, pp. 475-483, 2005.

[194] K. Dobrenis, H.-Y. Chang, M. H. Pina-Benabou et al., "Human and mouse microglia express connexin36, and functional gap junctions are formed between rodent microglia and neurons," Journal of Neuroscience Research, vol. 82, no. 3, pp. 306-315, 2005.

[195] A. D. Martínez, E. A. Eugenín, M. C. Brañes, M. V. Bennett, and J. C. Sáez, "Identification of second messengers that induce expression of functional gap junctions in microglia cultured from newborn rats," Brain Research, vol. 943, pp. 191-201, 2002.

[196] E. A. Eugenín, D. Eckardt, M. Theis, K. Willecke, M. V. L. Bennett, and J. C. Sáez, "Microglia at brain stab wounds express connexin 43 and in vitro form functional gap junctions after treatment with interferon- $\gamma$ and tumor necrosis factor- $\alpha$," Proceedings of the National Academy of Sciences of the United States of America, vol. 98, no. 7, pp. 4190-4195, 2001.

[197] J. I. Nagy, W. Li, E. L. Hertzberg, and C. A. Marotta, "Elevated connexin 43 immunoreactivity at sites of amyloid plaques in Alzheimer's disease," Brain Research, vol. 717, no. 1-2, pp. 173$178,1996$.

[198] K. S. Ásgeirsson, K. Ólafsdóttir, J. G. Jónasson, and H. M. Ógmundsdóttir, "The effects of IL- 6 on cell adhesion and Ecadherin expression in breast cancer," Cytokine, vol. 10, no. 9, pp. 720-728, 1998.

[199] F. Cao, R. Eckert, C. Elfgang et al., "A quantitative analysis of connexin-specific permeability differences of gap junctions expressed in HeLa transfectants and Xenopus oocytes," Journal of Cell Science, vol. 111, no. 1, pp. 31-43, 1998.

[200] C. Elfgang, R. Eckert, H. Lichtenberg-Frate et al., "Specific permeability and selective formation of gap junction channels in connexin-transfected HeLa cells," The Journal of Cell Biology, vol. 129, no. 3, pp. 805-817, 1995.

[201] G. Kanaporis, P. R. Brink, and V. Valiunas, "Gap junction permeability: selectivity for anionic and cationic probes," The American Journal of Physiology-Cell Physiology, vol. 300, no. 3, pp. C600-C609, 2011.

[202] R. Talaveron, E. R. Matarredona, R. R. de la Cruz, D. Macias, V. Galvez, and A. M. Pastor, "Implanted neural progenitor cells regulate glial reaction to brain injury and establish gap junctions with host glial cells," Glia, vol. 62, no. 4, pp. 623-638, 2014.
[203] H. Takeuchi, S. Jin, H. Suzuki et al., "Blockade of microglial glutamate release protects against ischemic brain injury," Experimental Neurology, vol. 214, no. 1, pp. 144-146, 2008.

[204] H. Takeuchi, H. Mizoguchi, Y. Doi et al., "Blockade of gap junction hemichannel suppresses disease progression in mouse models of amyotrophic lateral sclerosis and Alzheimer's disease," PLoS ONE, vol. 6, no. 6, Article ID e21108, 2011.

[205] Y. Imura, Y. Morizawa, R. Komatsu et al., "Microglia release ATP by exocytosis," GLIA, vol. 61, no. 8, pp. 1320-1330, 2013.

[206] C. Rigato, N. Swinnen, R. Buckinx et al., "Microglia proliferation is controlled by $\mathrm{P} 2 \mathrm{X} 7$ receptors in a pannexin1-independent manner during early embryonic spinal cord invasion," Journal of Neuroscience, vol. 32, no. 34, pp. 1155911573, 2012.

[207] J. Shijie, H. Takeuchi, I. Yawata et al., "Blockade of glutamate release from microglia attenuates experimental autoimmune encephalomyelitis in mice," The Tohoku Journal of Experimental Medicine, vol. 217, no. 2, pp. 87-92, 2009.

[208] J. Xiong, M. Burkovetskaya, N. Karpuk, and T. Kielian, "IL-1RI (interleukin-1 receptor type I) signalling is essential for host defence and hemichannel activity during acute central nervous system bacterial infection," ASN Neuro, vol. 4, no. 3, pp. 175-185, 2012.

[209] I. Yawata, H. Takeuchi, Y. Doi, J. Liang, T. Mizuno, and A. Suzumura, "Macrophage-induced neurotoxicity is mediated by glutamate and attenuated by glutaminase inhibitors and gap junction inhibitors," Life Sciences, vol. 82, no. 21-22, pp. 1111-1116, 2008.

[210] L. Endong, J. Shijie, Y. Sonobe et al., "The Gap-junction inhibitor Carbenoxolone suppresses the differentiation of Th17 cells through inhibition of IL-23 expression in antigen presenting cells," Journal of Neuroimmunology, vol. 240-241, pp. 58-64, 2011.

[211] A. Cerutti, M. Cols, and I. Puga, "Marginal zone B cells: virtues of innate-like antibody-producing lymphocytes," Nature Reviews Immunology, vol. 13, no. 2, pp. 118-132, 2013.

[212] A. Mantovani, M. A. Cassatella, C. Costantini, and S. Jaillon, "Neutrophils in the activation and regulation of innate and adaptive immunity," Nature Reviews Immunology, vol. 11, no. 8, pp. 519-531, 2011.

[213] G. P. Sandilands, J. McCrae, K. Hill, M. Perry, and D. Baxter, "Major histocompatibility complex class II (DR) antigen and costimulatory molecules on in vitro and in vivo activated human polymorphonuclear neutrophils," Immunology, vol. 119, no. 4, pp. 562-571, 2006.

[214] I. Müller, M. Munder, P. Kropf, and G. M. Hänsch, "Polymorphonuclear neutrophils and T lymphocytes: strange bedfellows or brothers in arms?" Trends in Immunology, vol. 30, no. 11, pp. 522-530, 2009.

[215] C. Beauvillain, Y. Delneste, M. Scotet et al., "Neutrophils efficiently cross-prime naive T cells in vivo," Blood, vol. 110, no. 8, pp. 2965-2973, 2007.

[216] D. S. A. Abdallah, C. E. Egan, B. A. Butcher, and E. Y. Denkers, "Mouse neutrophils are professional antigen-presenting cells programmed to instruct Th1 and Th17 T-cell differentiation," International Immunology, vol. 23, no. 5, pp. 317-326, 2011.

[217] M. C. Brañes, J. E. Contreras, and J. C. Sáez, "Activation of human polymorphonuclear cells induces formation of functional gap junctions and expression of connexins," Medical Science Monitor, vol. 8, pp. R313-R323, 2002.

[218] H. K. Eltzschig, T. Eckle, A. Mager et al., "ATP release from activated neutrophils occurs via connexin 43 and modulates 
adenosine-dependent endothelial cell function," Circulation Research, vol. 99, no. 10, pp. 1100-1108, 2006.

[219] S. Zahler, A. Hoffmann, T. Gloe, and U. Pohl, "Gap-junctional coupling between neutrophils and endothelial cells: a novel modulator of transendothelial migration," Journal of Leukocyte Biology, vol. 73, no. 1, pp. 118-126, 2003.

[220] M. Z. R. Sarieddine, K. E. L. Scheckenbach, B. Foglia et al., "Connexin43 modulates neutrophil recruitment to the lung," Journal of Cellular and Molecular Medicine, vol. 13, no. 11-12, pp. 4560-4570, 2009.

[221] I. Scerri, O. Tabary, T. Dudez et al., "Gap junctional communication does not contribute to the interaction between neutrophils and airway epithelial cells," Cell Communication \& Adhesion, vol. 13, no. 1-2, pp. 1-12, 2006.

[222] P. Coutinho, C. Qiu, S. Frank et al., "Limiting burn extension by transient inhibition of Connexin 43 expression at the site of injury," The British Journal of Plastic Surgery, vol. 58, no. 5, pp. 658-667, 2005.

[223] M. Cronin, P. N. Anderson, J. E. Cook, C. R. Green, and D. L. Becker, "Blocking connexin 43 expression reduces inflammation and improves functional recovery after spinal cord injury," Molecular and Cellular Neuroscience, vol. 39, no. 2, pp. 152-160, 2008.

[224] C. Qiu, P. Coutinho, S. Frank et al., "Targeting connexin43 expression accelerates the rate of wound repair," Current Biology, vol. 13, no. 19, pp. 1697-1703, 2003.

[225] S. Rignault, J. Haefliger, B. Waeber, L. Liaudet, and F. Feihl, "Acute inflammation decreases the expression of connexin 40 in mouse lung," Shock, vol. 28, no. 1, pp. 78-85, 2007.

[226] Y. Bao, Y. Chen, C. Ledderose, L. Li, and W. G. Junger, "Pannexin 1 channels link chemoattractant receptor signaling to local excitation and global inhibition responses at the front and back of polarized neutrophils," The Journal of Biological Chemistry, vol. 288, no. 31, pp. 22650-22657, 2013.

[227] Y. Chen, Y. Yao, Y. Sumi et al., "Purinergic signaling: a fundamental mechanism in neutrophil activation," Science Signaling, vol. 3, no. 125, p. ra45, 2010.

[228] O. Thaunat, A. G. Granja, P. Barral et al., "Asymmetric segregation of polarized antigen on B cell division shapes presentation capacity," Science, vol. 335, no. 6067, pp. 475-479, 2012.

[229] M.-I. Yuseff, P. Pierobon, A. Reversat, and A.-M. LennonDuménil, "How B cells capture, process and present antigens: a crucial role for cell polarity," Nature Reviews Immunology, vol. 13, no. 7, pp. 475-486, 2013.

[230] S. Machtaler, M. Dang-Lawson, K. Choi, C. Jang, C. C. Naus, and L. Matsuuchi, "The gap junction protein Cx43 regulates Blymphocyte spreading and adhesion," Journal of Cell Science, vol. 124, no. 15, pp. 2611-2621, 2011.

[231] E. Oviedo-Orta, T. Hoy, and W. H. Evans, "Intercellular communication in the immune system: differential expression of connexin 40 and 43 , and perturbation of gap junction channel functions in peripheral blood and tonsil human lymphocyte subpopulations," Immunology, vol. 99, no. 4, pp. 578-590, 2000.

[232] L. Falk, M. Dang-Lawson, J. L. Vega et al., "Mutations of Cx43 that affect B cell spreading in response to BCR signaling," Biology Open, vol. 3, pp. 185-194, 2014.

[233] S. Machtaler, K. Choi, M. Dang-Lawson et al., "The role of the gap junction protein connexin 43 in B lymphocyte motility and migration," FEBS Letters, vol. 588, no. 8, pp. 1249-1258, 2014.

[234] C. Théry, M. Ostrowski, and E. Segura, "Membrane vesicles as conveyors of immune responses," Nature Reviews Immunology, vol. 9, no. 8, pp. 581-593, 2009.
[235] S. C. Watkins and R. D. Salter, "Functional connectivity between immune cells mediated by tunneling nanotubules," Immunity, vol. 23, no. 3, pp. 309-318, 2005.

[236] E. Oviedo-Orta and W. H. Evans, "Gap junctions and connexins: potential contributors to the immunological synapse," Journal of Leukocyte Biology, vol. 72, no. 4, pp. 636-642, 2002.

[237] H. D. Moreau and P. Bousso, "Visualizing how T cells collect activation signals in vivo," Current Opinion in Immunology, vol. 26, pp. 56-62, 2014.

[238] H. D. Moreau, F. Lemaître, E. Terriac et al., "Dynamic in situ cytometry uncovers $\mathrm{T}$ cell receptor signaling during immunological synapses and kinapses in vivo," Immunity, vol. 37, no. 2, pp. 351-363, 2012.

[239] C. M. Wang, C. Ploia, F. Anselmi, A. Sarukhan, and A. Viola, "Adenosine triphosphate acts as a paracrine signaling molecule to reduce the motility of T cells," The EMBO Journal, vol. 33, no. 12, pp. 1354-1364, 2014.

[240] H. Benlalam, T. Carré, A. Jalil et al., "Regulation of gap junctions in melanoma and their impact on Melan-A/MART-1-specific $\mathrm{CD}^{+}$T lymphocyte emergence," Journal of Molecular Medicine, vol. 91, no. 10, pp. 1207-1220, 2013.

[241] M. Kuczma, J. R. Lee, and P. Kraj, "Connexin 43 signaling enhances the generation of Foxp3+ regulatory T cells," Journal of Immunology, vol. 187, no. 1, pp. 248-257, 2011.

[242] E. Oviedo-Orta, M. Perreau, W. H. Evans, and I. Potolicchio, "Control of the proliferation of activated $\mathrm{CD}^{+} \mathrm{T}$ cells by connexins," Journal of Leukocyte Biology, vol. 88, no. 1, pp. 7986, 2010.

[243] U. Schenk, A. M. Westendorf, E. Radaelli et al., "Purinergic control of T cell activation by ATP released through pannexin-1 hemichannels," Science Signaling, vol. 1, no. 39, p. ra6, 2008.

[244] K. F. Shoji, PJ. Sáez, P. Harcha, H. L. Aguila, and J. C. Sáez, "Pannexinl channels act downstream of P2X receptors in ATPinduced murine T-cell death," Channels, vol. 8, no. 2, pp. 142156, 2014.

[245] T. Woehrle, L. Yip, A. Elkhal et al., "Pannexin-1 hemichannelmediated ATP release together with $\mathrm{P} 2 \mathrm{X} 1$ and $\mathrm{P} 2 \mathrm{X} 4$ receptors regulate T-cell activation at the immune synapse," Blood, vol. 116, no. 18, pp. 3475-3484, 2010.

[246] T. Woehrle, L. Yip, M. Manohar et al., "Hypertonic stress regulates $\mathrm{T}$ cell function via pannexin-1 hemichannels and $\mathrm{P} 2 \mathrm{X}$ receptors," Journal of Leukocyte Biology, vol. 88, no. 6, pp. 1181$1189,2010$.

[247] E. Oviedo-Orta, P. Gasque, and W. H. Evans, "Immunoglobulin and cytokine expression in mixed lymphocyte cultures is reduced by disruption of gap junction intercellular communication," FASEB Journal, vol. 15, no. 3, pp. 768-774, 2001.

[248] E. Oviedo-Orta, R. J. Errington, and W. H. Evans, "Gap junction intercellular communication during lymphocyte transendothelial migration," Cell Biology International, vol. 26, no. 3, pp. 253263, 2002.

[249] U. Luckey, T. Schmidt, N. Pfender et al., "Crosstalk of regulatory $\mathrm{T}$ cells and tolerogenic dendritic cells prevents contact allergy in subjects with low zone tolerance," The Journal of Allergy and Clinical Immunology, vol. 130, no. 3, pp. 781.e11-797.e11, 2012.

[250] M. E. Moreno-Fernandez, C. M. Rueda, L. K. Rusie, and C. A. Chougnet, "Regulatory T cells control HIV replication in activated T cells through a cAMP-dependent mechanism," Blood, vol. 117, no. 20, pp. 5372-5380, 2011.

[251] T. D. Nguyen and S. M. Taffet, "A model system to study Connexin 43 in the immune system," Molecular Immunology, vol. 46, no. 15, pp. 2938-2946, 2009. 
[252] G. Dahl, "Gap junction-mimetic peptides do work, but in unexpected ways," Cell Communication and Adhesion, vol. 14, no. 6, pp. 259-264, 2007.

[253] A. J. Siller-Jackson, S. Burra, S. Gu et al., "Adaptation of connexin 43-hemichannel prostaglandin release to mechanical loading," The Journal of Biological Chemistry, vol. 283, no. 39, pp. 26374-26382, 2008.

[254] M. A. Riquelme, R. Kar, S. Gu, and J. X. Jiang, "Antibodies targeting extracellular domain of connexins for studies of hemichannels," Neuropharmacology, vol. 75, pp. 525-532, 2013. 


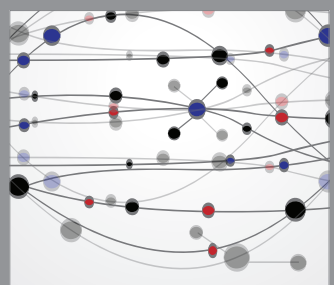

The Scientific World Journal
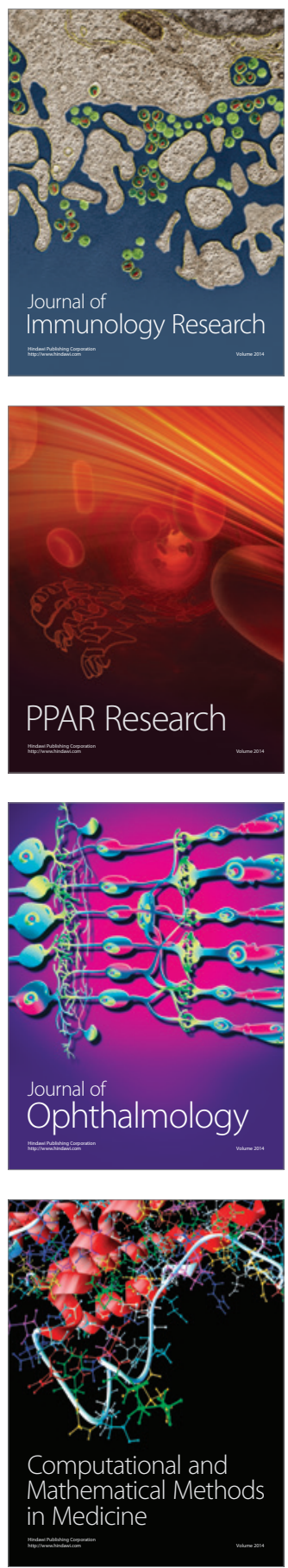

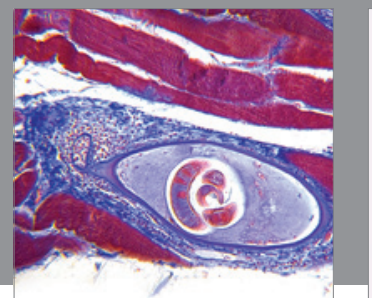

Gastroenterology

Research and Practice
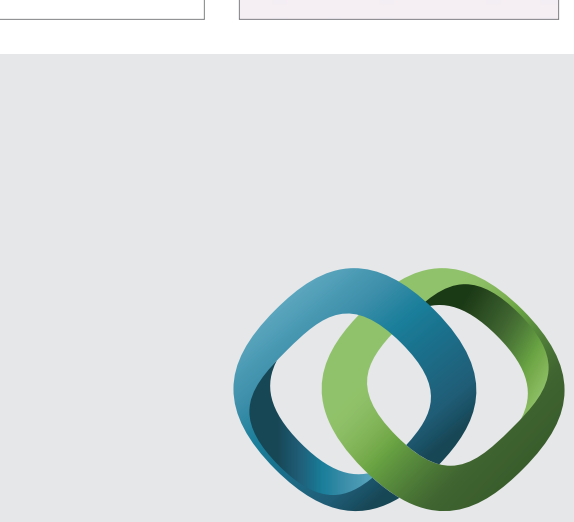

\section{Hindawi}

Submit your manuscripts at

http://www.hindawi.com
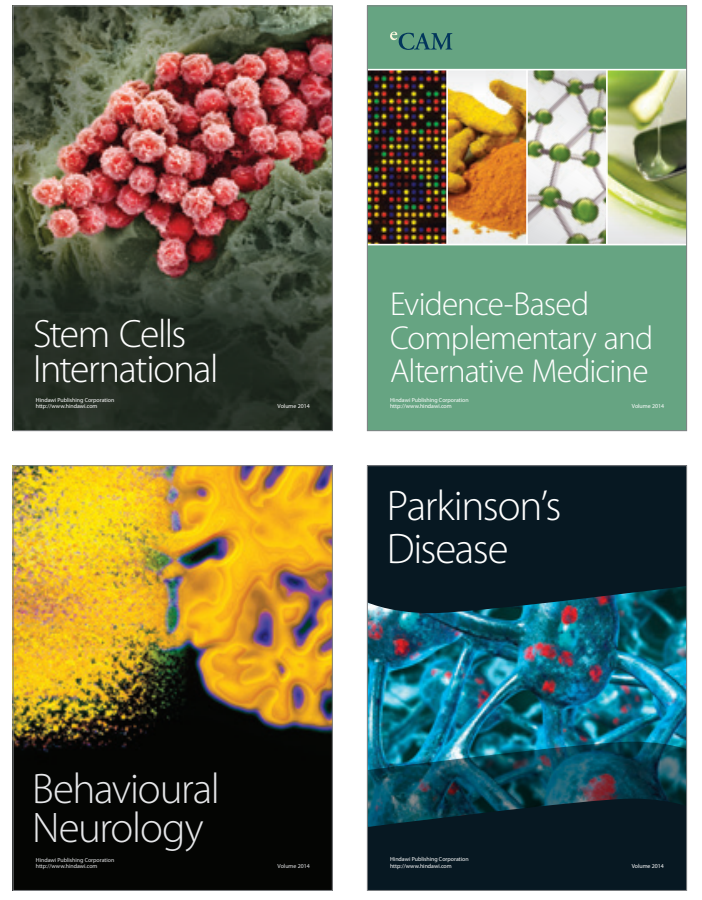
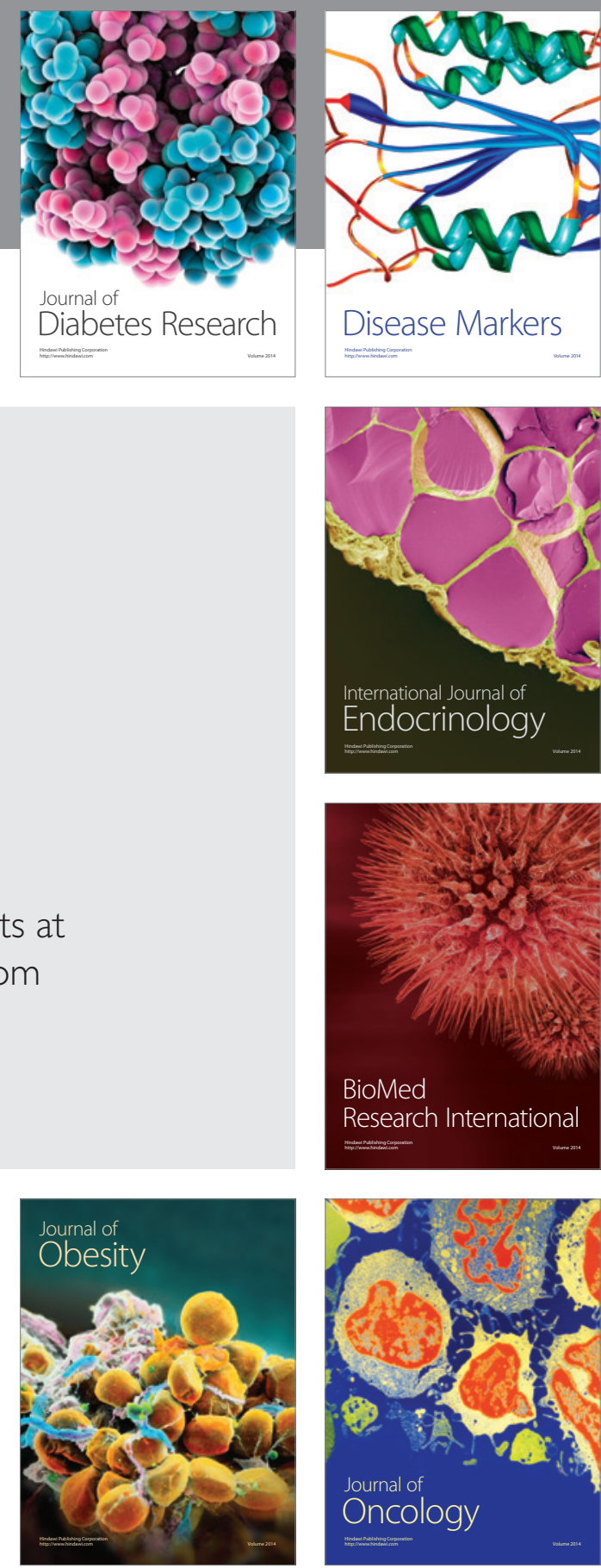

Disease Markers
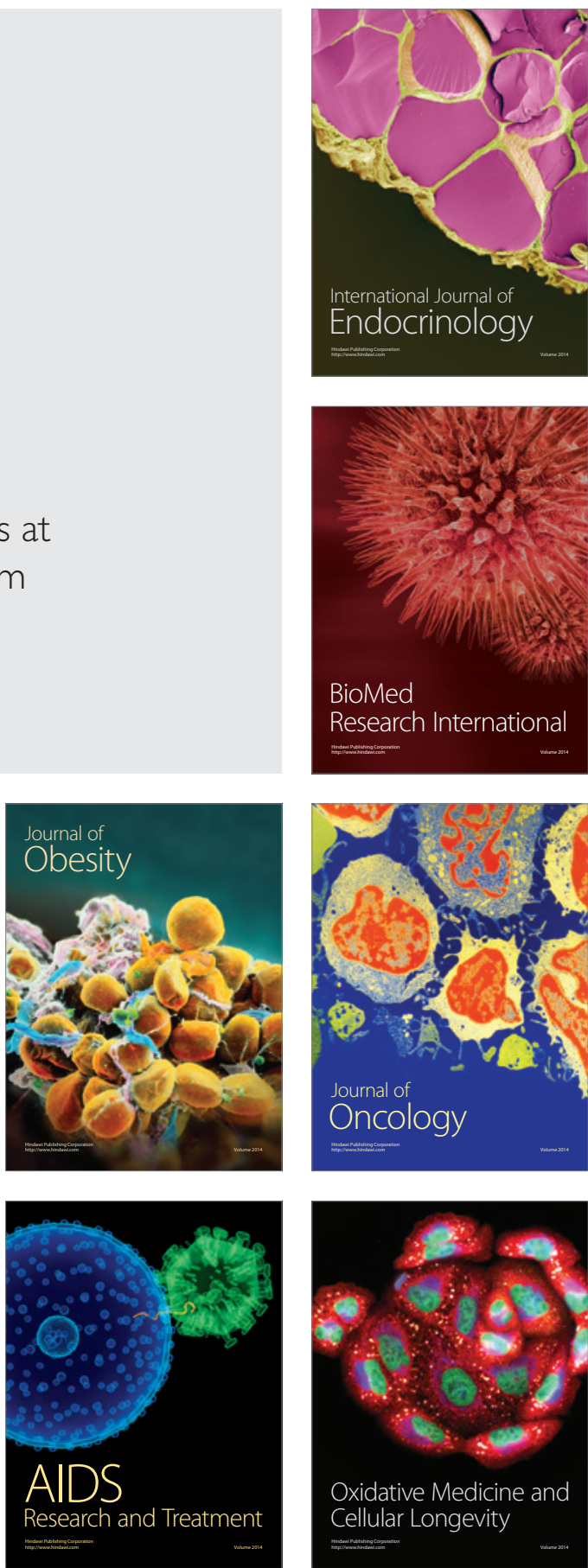